\title{
Potentially poisonous plastic particles: microplastics as a vector for cyanobacterial toxins microcystin-LR and microcystin-LF.
}

PESTANA, C.J., MOURA, D.S., CAPELO-NETO, J., EDWARDS, C., DREISBACH, D., SPENGLER, B. and LAWTON, L.A. 


\section{Potentially Poisonous Plastic Particles: Microplastics as a Vector for Cyanobacterial Toxins Microcystin-LR and Microcystin-LF}

Carlos J. Pestana,* Diana S. Moura, José Capelo-Neto, Christine Edwards, Domenic Dreisbach, Bernhard Spengler, and Linda A. Lawton

Cite This: Environ. Sci. Technol. 2021, 55, 15940-15949

Read Online

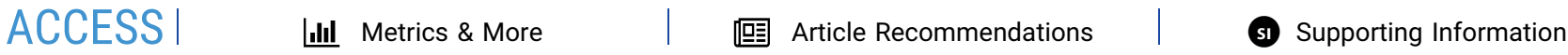

ABSTRACT: The potential of microplastics to act as a vector for micropollutants of natural or anthropogenic origin is of rising concern. Cyanobacterial toxins, including microcystins, are harmful to humans and wildlife. In this study, we demonstrate for the first time the potential of microplastics to act as vectors for two different microcystin analogues. A concentration of up to 28 times from water to plastic was observed for the combination of polystyrene and microcystin-LF achieving toxin concentrations on the plastic of $142 \pm 7 \mu \mathrm{g} \mathrm{g}^{-1}$. Based on the experimental results, and assuming a worst-case scenario, potential toxin doses for daphnids are calculated based on published microplastic ingestion data. Progressing up through trophic levels, theoretically, the concentration of microcystins in organisms is discussed. The experimental results indicate that adsorption of microcystins onto microplastics is a multifactorial

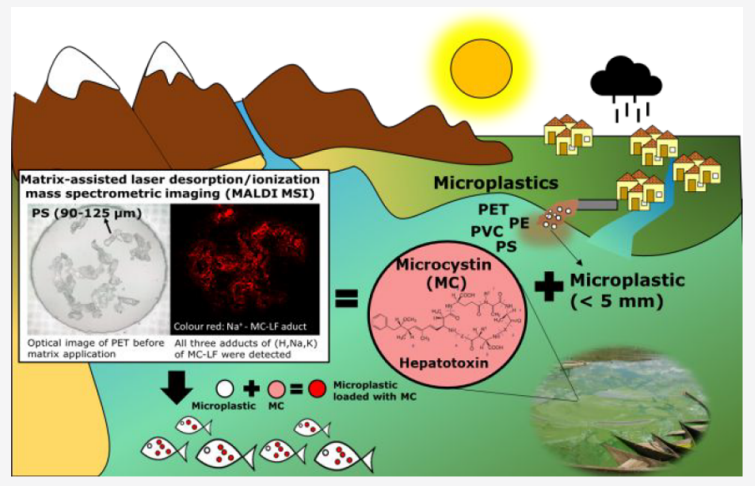
process, depending on the particle size, the variable amino acid composition of the microcystins, the type of plastic, and $\mathrm{pH}$. Furthermore, the results of the current study stressed the limitations of exclusively investigating microcystin-LR (the most commonly studied microcystin congener) as a model compound representing a group of around 250 reported microcystin congeners.

KEYWORDS: microcystins, microplastics, trophic accumulation, freshwater, cyanotoxins, cyanobacteria

\section{INTRODUCTION}

Plastics are ubiquitous in the world with estimated 299 million tonnes produced in 2013. ${ }^{1}$ According to Plastics Europe, ${ }^{2} 80 \%$ of plastics produced are polyethylene, polyvinyl chloride, polystyrene, polyethylene terephthalate, polypropylene, and polyurethane. At the end of their life cycle, most plastics will enter the environment. Consumer plastic waste can enter wastewater treatment plants, where breakthrough can occur leading to plastic particles reaching the freshwater environment. ${ }^{1}$ Larger plastic particles are reduced by physical, chemical, and biological processes; ${ }^{3}$ plastic particles thus reduced to sizes of $\leq 5 \mathrm{~mm}$ (in all dimensions) are considered microplastics. Another source of microplastics are particles originally manufactured in microplastic dimensions, for example, beads for abrasive blasting used in coatings and paints. Microplastic occurrence in aquatic systems globally has been recognized as an environmental risk factor ${ }^{4-8}$ as it has been found that microplastic particles can be contaminated with organic pollutants. ${ }^{9}$ Microplastics act as mobile reservoirs of toxic compounds due to their high surface-to-volume ratio. Adsorption is a surface process and therefore a high surface-tovolume ratio favors adsorption of increased amounts of pollutants. $^{9-11}$ Microplastics, including any adsorbed contaminants, can enter the food web by ingestion by aquatic organisms such as fish, zooplankton, and crustaceans where desorption in the gut can lead to bioaccumulation of the contaminants in the food web. ${ }^{7}$

Cyanobacteria and their secondary metabolites are encountered in most aquatic systems globally. During blooms, seasonal or perennial mass occurrences of cyanobacteria, high concentrations of potentially toxic secondary metabolites can be detected in the surrounding water. ${ }^{12}$ Evidence suggests that with increasing global warming, the frequency and intensity of blooms will increase. ${ }^{13,14}$ One of the most frequently reported groups of cyanobacterial toxins is microcystins (MCs) with over 240 congeners. ${ }^{15}$ MCs are hepatotoxic heptapeptides with two variable amino acids that inhibit protein phosphatases and can act as tumor promoters. Different congeners of MC display different chemical behaviors due to their amino acid composition and other chemical differences such as (de)methylation. MC-LR is one of the most

Received: August 27, 2021

Revised: October 26, 2021

Accepted: October 27, 2021

Published: November 11, 2021

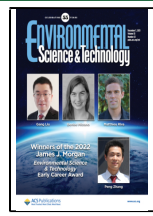



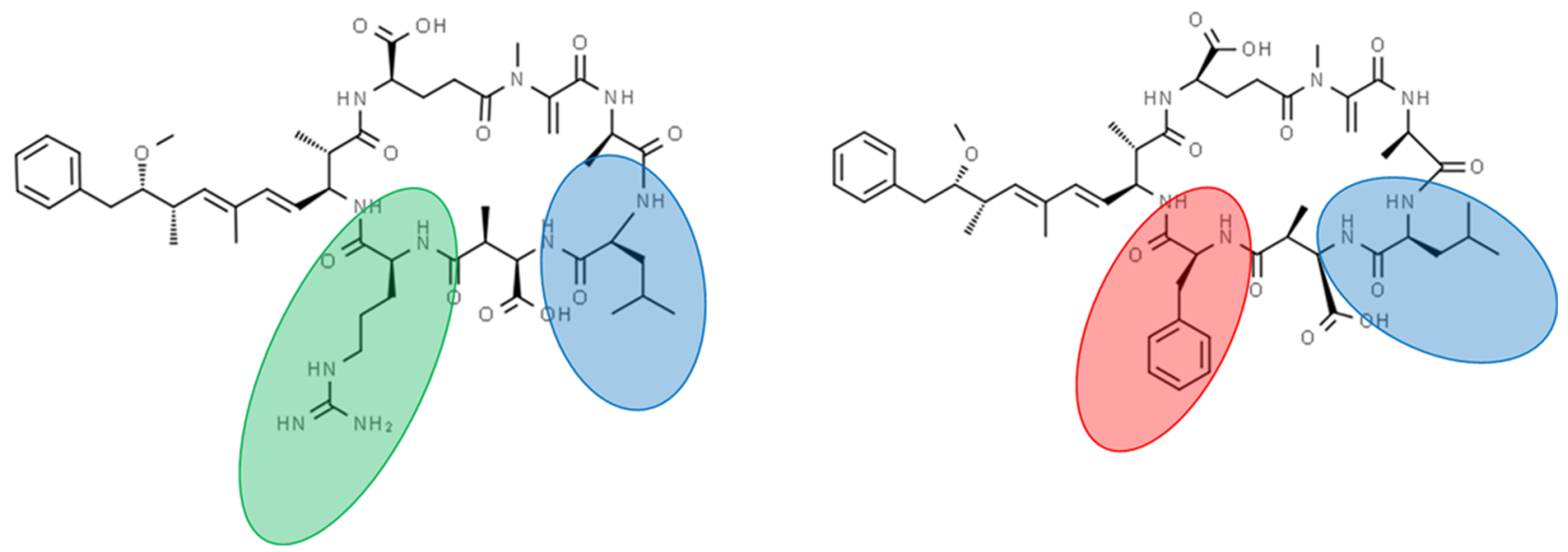

Figure 1. Chemical structures of the two MC congeners used in the present study (MC-LR left and MC-LF right) with variable amino acids indicating leucine (blue) and arginine (green) (MC-LR) and leucine (blue) and phenylalanine (red) (MC-LF). ${ }^{21,22}$ The variable amino acids within the MC structure are largely responsible for the overall hydrophobicity of the congener.

commonly reported analogues; however, MC-LF is of increasing concern as it presents similar toxicity but is more hydrophobic and thus more readily enters the target organs (Figure 1). ${ }^{16-20}$

The World Health Organization (WHO) has set a recommended maximum allowable level of $1 \mu \mathrm{g} \mathrm{L} \mathrm{L}^{-1}$ of total MCs in potable water. ${ }^{23,24}$ Currently, little is known about the partitioning of MCs on microplastics. MC-contaminated microplastics could pose a significant environmental risk acting as a concentration vehicle and unlike other natural particulates and sediment microplastics can be mistaken as food by aquatic biota representing a gateway into the food web via ingestion by aquatic organisms.

With increased frequency of toxic cyanobacterial blooms and increasing microplastic presence in freshwater systems, it stands to reason that co-occurrence of microplastic particles and MCs frequently takes place.

Thus, the current study sets out to determine, for the first time, if microplastic particles can act as a vector for MCs. Four different plastics (polystyrene [PS], polyvinyl chloride [PVC], polyethylene $[\mathrm{PE}]$, and polyethylene terephthalate $[\mathrm{PET}]$ ) were exposed to two MC congeners (MC-LR and MC-LF). The effects of $\mathrm{pH}$, exposure time, and particle size were evaluated. Furthermore, an estimate of the amount of toxin that could be transported into the food web by microplastics was made.

\section{MATERIALS AND METHODS}

All plastics were obtained from Goodfellows Ltd. (UK) and processed to produce microplastics of known sizes. PVC was received as $1 \mathrm{~m}$ rods ( $5 \mathrm{~mm}$ diameter) and cut into approximately $5 \mathrm{~mm}$ length with stainless steel shears. The remaining three plastics (PS, PE, and PET) were received as pellets $(3-5 \mathrm{~mm})$. The material received was characterized by Fourier transform infrared (FTIR) spectroscopy (Nicolet iS10, Thermo Fisher Scientific, UK) to confirm the polymers received. All plastics were reduced in size individually in an industrial stainless steel blender (Waring, USA). Size reduction was achieved by pulsing the blender for $20 \mathrm{~s}$ with $1-2 \mathrm{~min}$ cooling intervals to avoid thermally altering the plastics. Sizereduced plastics were then sieved to three standardized specific particles sizes of $>1 \mathrm{~mm}$ (and $<5 \mathrm{~mm}$ ), $0.25-0.5 \mathrm{~mm}$, and 0.09-0.125 mm (sieves from Fisher Scientific, UK; sieving apparatus from Retsch Ltd., UK). Artificial freshwater (AFW), used as the experimental medium, was prepared with ultrapure water $(18.2 \mathrm{M} \Omega)$ and the addition of $\mathrm{CaCl}_{2} 2 \mathrm{H}_{2} \mathrm{O}(58.5 \mathrm{mg}$ $\left.\mathrm{L}^{-1}\right), \mathrm{MgSO}_{4} 7 \mathrm{H}_{2} \mathrm{O}\left(24.7 \mathrm{mg} \mathrm{L}{ }^{-1}\right), \mathrm{NaHCO}_{3}\left(12.0 \mathrm{mg} \mathrm{L}^{-1}\right)$, and $\mathrm{KCl}\left(1.2 \mathrm{mg} \mathrm{L}^{-1}\right){ }^{25}$ The $\mathrm{pH}$ was adjusted to the required level ( $\mathrm{pH}$ 2, $\mathrm{pH} 5, \mathrm{pH}$ 7, $\mathrm{pH}$ 9, and $\mathrm{pH}$ 11) either with $\mathrm{HNO}_{3}$ or $\mathrm{NaOH}$. MC (LR or LF) solutions $\left(5 \mu \mathrm{g} \mathrm{mL}^{-1}\right)$ in AFW were prepared and combined with the individual microplastics $\left(10 \mathrm{~g} \mathrm{~L}^{-1}\right)$. All $\mathrm{pH}$ conditions were tested with the three sizes for each plastic and a control sample containing no plastic particles. Samples were continuously horizontally agitated on an orbital shaker at $250 \mathrm{rpm}$ and $25^{\circ} \mathrm{C}$ in the dark for $48 \mathrm{~h}$. Samples $(100 \mu \mathrm{L})$ were extracted with a glass syringe with a stainless steel needle at time points $0,2,6,12,24$, and $48 \mathrm{~h}$ and spin-filtered in microcentrifuge filter tubes $(0.22 \mu \mathrm{m}$ cellulose acetate filters, Corning, USA); these polypropylene filter tubes displayed $<2 \%$ adsorption of MC congeners (data not shown) and were deemed safe for use. Samples were directly analyzed by HPLC-PDA (Section S2.2). Controls containing no microplastics were prepared for all conditions. All experiments and controls were conducted in triplicate. In all experiments, contact between MCs and any types of plastics other than the tested type of microplastic was eliminated.

To confirm the presence of MC-LF on the surface of PS, samples were prepared for 3D surface matrix-assisted laser desorption/ionization (MALDI) mass spectrometry imaging (MSI) according to the study of Kompauer et al.; ${ }^{26}$ in short, a sample $(2 \mu \mathrm{L})$ of a suspension containing $10 \mathrm{~g} \mathrm{~L}^{-1}$ PS (0.09$0.125 \mathrm{~mm}$ particle size) that had been exposed to MC-LF for $48 \mathrm{~h}$ was applied to a PTFE-coated glass slide and dried for 30 min in a desiccator. A matrix solution of $30 \mathrm{mg} \mathrm{mL}^{-1} 2,5$ dihydroxybenzoic acid in acetone/water (0.2\% TFA) $1: 1 \mathrm{v} / \mathrm{v}$ was freshly prepared, and a volume of $80 \mu \mathrm{L}$ was sprayed onto the sample surface with a flow rate of $10 \mu \mathrm{L} \mathrm{min}{ }^{-1}$ and a rotation of $500 \mathrm{rpm}$ using an ultrafine pneumatic sprayer system (SMALDIPrep, TransMIT GmbH, Germany). 3D optical microscope images of the sample surface were obtained with a Keyence VHX-5000 digital microscope (Keyence Deutschland $\mathrm{GmbH}$, Germany) before and after matrix application. For data acquisition, Xcalibur software on a $Q$ Exactive HF orbital trapping mass spectrometer (Thermo Fisher Scientific GmbH, Germany) equipped with an APSMALDI5 AF (TransMIT GmbH, Germany) MSI system was 


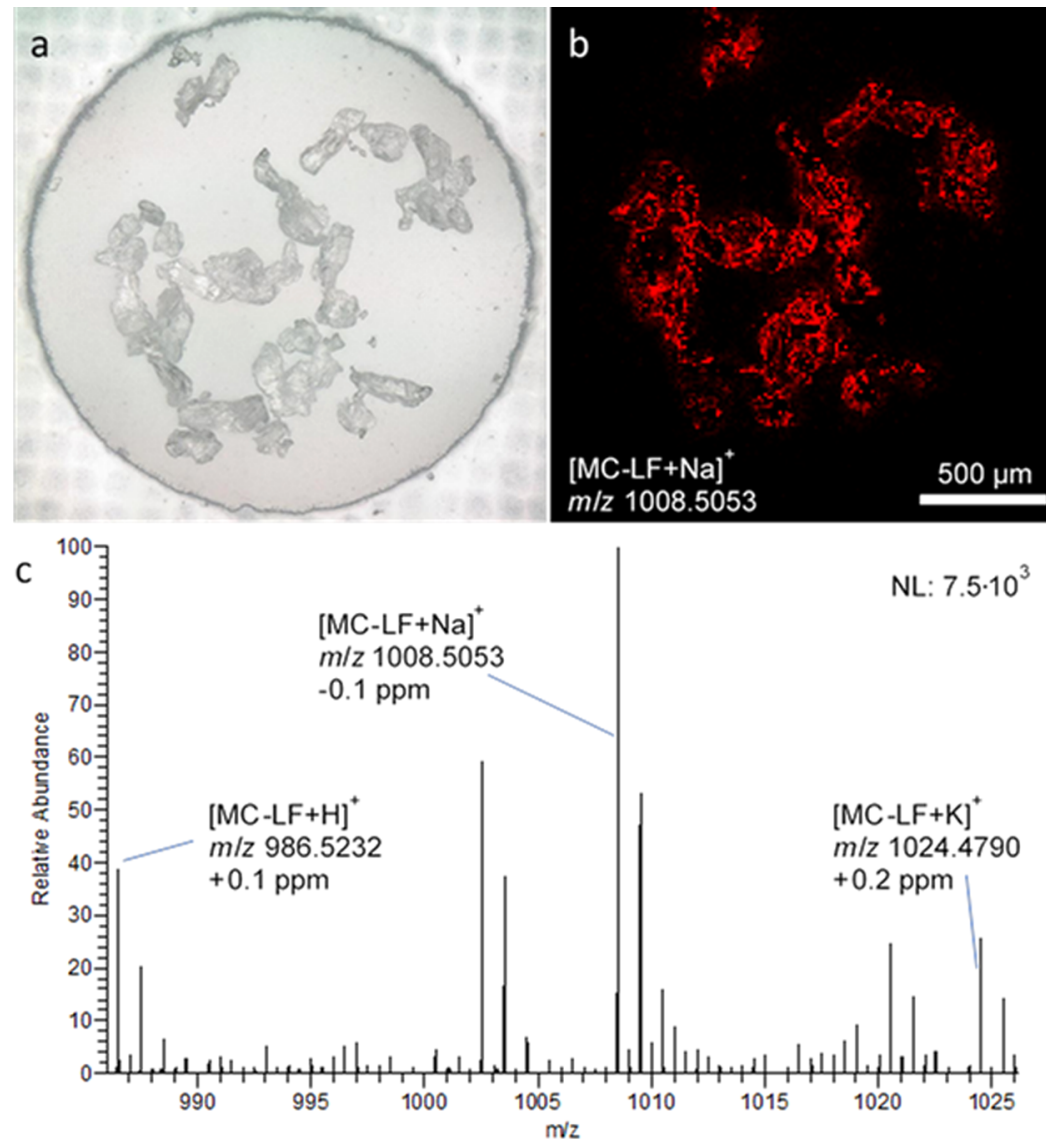

Figure 2. 3D surface MALDI MSI of MC-LF adsorbed to the PS microplastic. (a) Optical microscope image of PS particles before matrix application. (b) MS image showing the spatial distribution of $[\mathrm{MC}-\mathrm{LF}+\mathrm{Na}]^{+}$at $\mathrm{m} / z$ 1008.5053. (c) Single-pixel mass spectrum for a mass range $m / z$ of 985 to 1025 obtained from the PS microplastic. Three different adducts for MC-LF were labeled with measured mass and mass deviation. MS images were generated with $170 \times 174$ pixels, a pixel size of $12 \mu \mathrm{m}$, and an image bin width of $\Delta(\mathrm{m} / z)=0.01$. The scale bar is $500 \mu \mathrm{m}$.

used. Ion images of selected $\mathrm{m} / z$ values were generated using Mirion imaging software ${ }^{27}$ with a mass bin width of $\Delta(\mathrm{m} / z)=$ 0.01 . MS images were normalized to the highest intensity measured for each ion separately. No further image processing steps such as smoothing, interpolation, or TIC normalization were employed.

The zeta potential of the plastics in the experimental medium under $\mathrm{pH}$ 3-10 was measured using a Malvern Zetasizer instrument (Nano ZS, UK, Table S3).

A $t$-test was performed to determine significance testing (Supporting Information S6). Pearson correlation $\left(R^{2}\right)$ was used to evaluate the relationship between the variables. For all statistical tests, a significance level ( $p$ value) of $5 \%$ was set.

\section{RESULTS AND DISCUSSION}

Microplastics are encountered in aquatic systems globally, ${ }^{2,28}$ and a number of studies ${ }^{4-8,29,30}$ have demonstrated that microplastics can act as a vehicle for the concentration of organic pollutants such as pyrene, phenanthrene, bis-2ethylhxyl phthalate, and dichlorodiphenyltrichloroethane. In the present study, we were able to demonstrate that three sizes of microplastics, small $(0.09-0.125 \mathrm{~mm})$, medium (0.25-0.5 $\mathrm{mm})$, and large size $(>1 \mathrm{~mm})$, can also act as a concentration vehicle for MCs (Figure 2). Throughout the study, adsorption of MC was determined by the reduction in the MC concentration in solution compared to controls without microplastics. Typically used in biomedical science, MALDI
MSI provides untargeted and label-free analysis of various molecular classes in the spatial context of tissues and cells. Here, recent technical developments in 3D surface MALDI $\mathrm{MSI}^{26}$ were utilized to confirm the adsorption of MC congeners on plastic surfaces.

The obtained 3D surface MALDI MSI results clearly show the adsorption of MC-LF on the surface of the PS particles. All three adducts $\left(\mathrm{H}^{+}, \mathrm{Na}^{+}\right.$, and $\left.\mathrm{K}^{+}\right)$of MC-LF were detected and assigned, based on accurate mass measurements (Figure 2c), showing identical spatial distributions (Figure $2 \mathrm{~b}$ for [MC-LF $+\mathrm{Na}]^{+}$and Figure $\mathrm{S} 5$ for $[\mathrm{MC}-\mathrm{LF}+\mathrm{H}]^{+}$and $[\mathrm{MC}-\mathrm{LF}+\mathrm{K}]^{+}$). By comparing the optical image with the ion images, the MSI results demonstrate that MC-LF was primarily detected on PS particles, thus unambiguously confirming adsorption to the surface of the plastic particle and directly visualizing MCs adsorbed to the microplastic for the first time.

The adsorption behavior of both MC-LR and MC-LF onto four different microplastics was investigated by monitoring the diminishing toxin concentration in solution, and a control containing no microplastic particles was also analyzed at each $\mathrm{pH}$ to monitor the toxin stability at the corresponding $\mathrm{pH}$ concentration (Figure 3). The MC-LR concentration was stable under all tested $\mathrm{pH}$ concentrations with a maximum toxin loss of $20 \%$ at $\mathrm{pH} 2$ and no more than $9 \%$ loss at $\mathrm{pH} 5-$ 11. The MC-LF concentration was also comparatively stable at $\mathrm{pH} 5-11$ with a decrease of no more than $14 \%$ over time. At $\mathrm{pH} 2$, the toxin concentration decreased by $43 \%$ over the first 6 $\mathrm{h}$ of the experiment with a final loss of $44 \%$ after $48 \mathrm{~h}$. Harada 
Microcystin (LR)
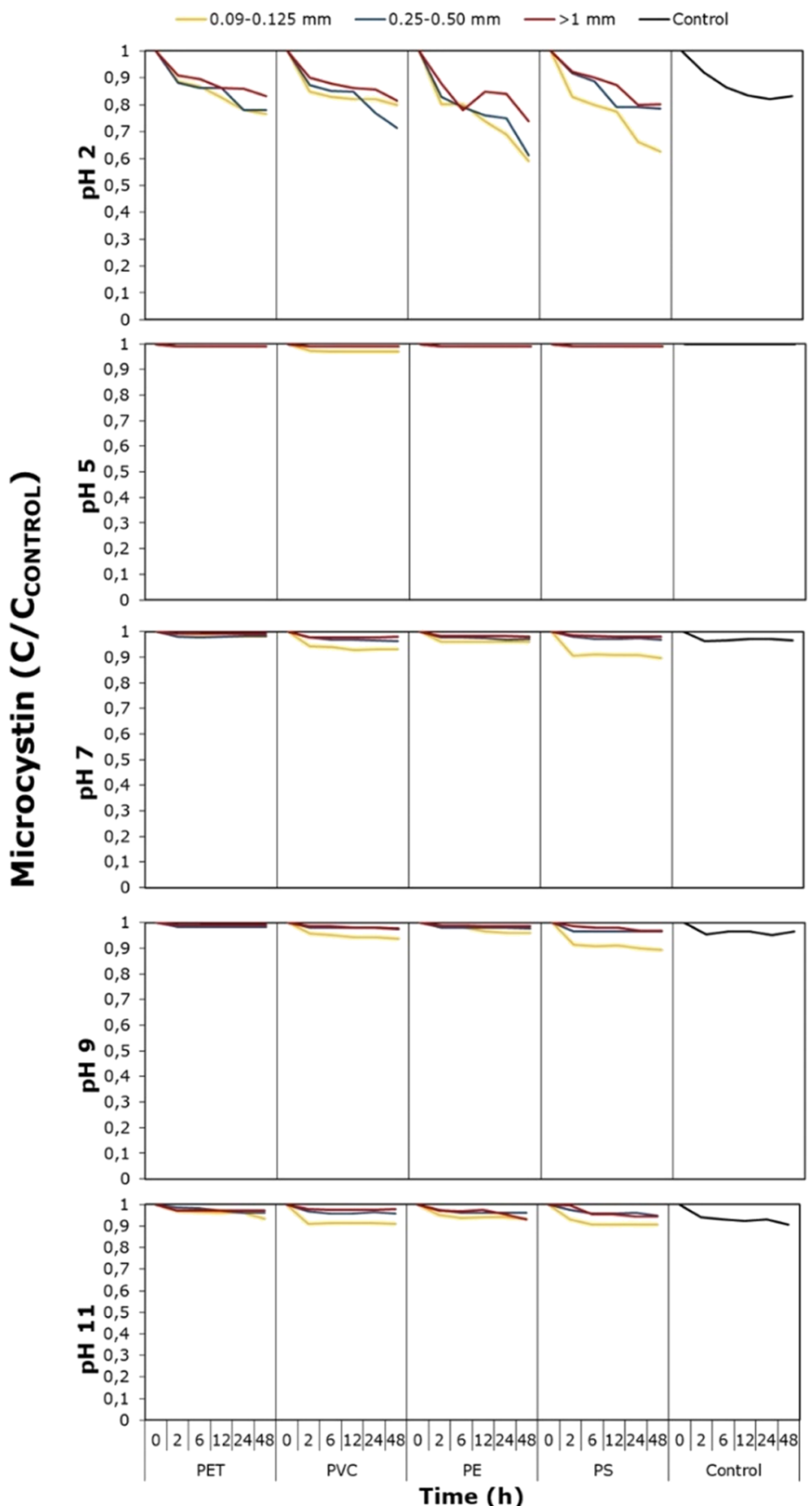

Microcystin (LF)
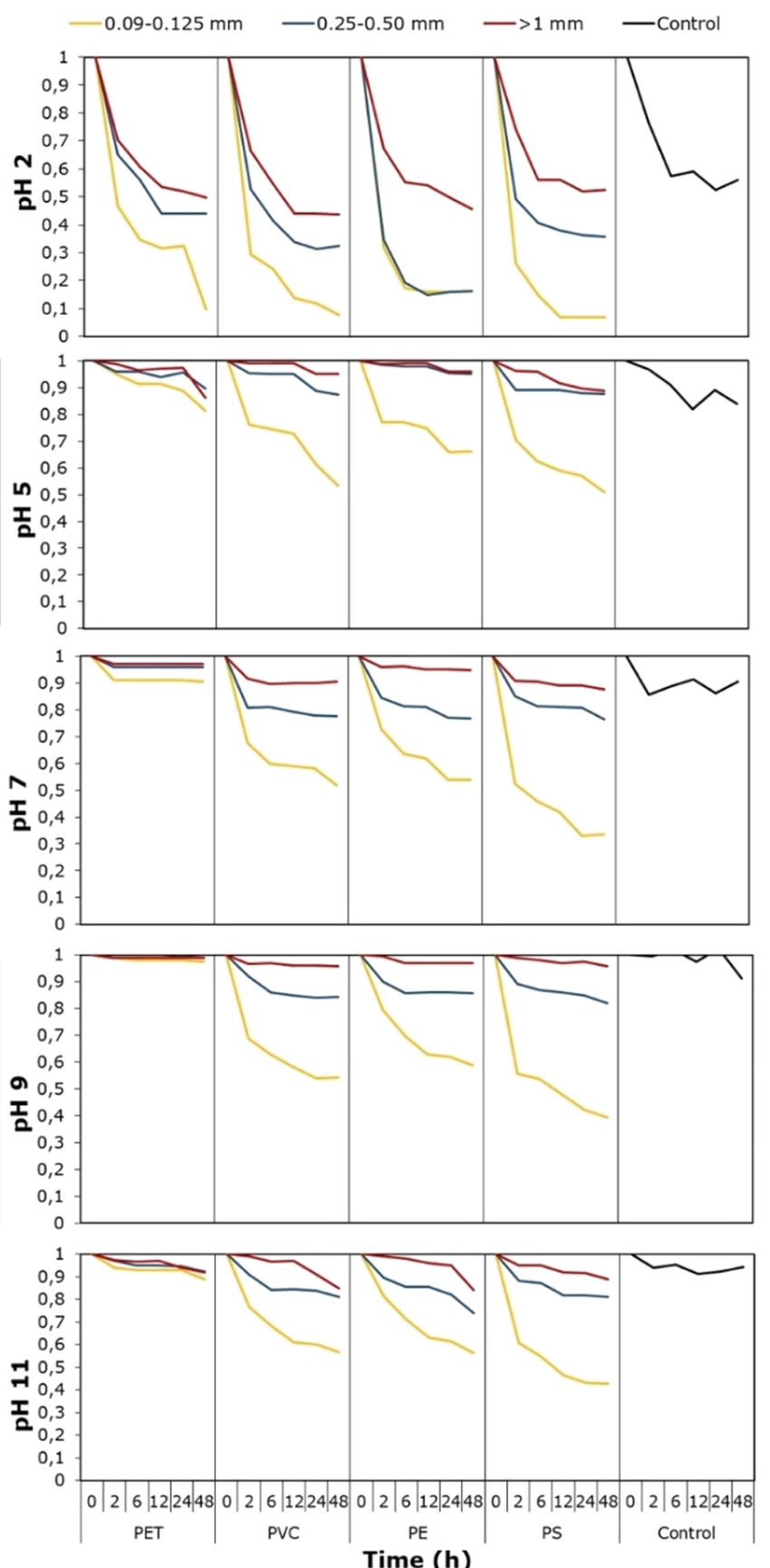

Figure 3. Influence of $\mathrm{pH}$ on MC-LR and MC-LF adsorption onto PS, PVC, PE, and PET particles of different sizes $(>1 \mathrm{~mm}$ [red], $0.25-0.50 \mathrm{~mm}$ [blue], and 0.009-0.125 mm [yellow]) (Test conditions: $10 \mathrm{~g} \mathrm{~L}^{-1}$ plastics, $5 \mu \mathrm{g} \mathrm{mL}^{-1} \mathrm{MC}, 48 \mathrm{~h}$ agitation time, $25^{\circ} \mathrm{C}$, and control [black] contained no microplastic). $\% \mathrm{RSD} \leq 10 \%, n=3$.

et al. ${ }^{31}$ had previously reported on the detrimental effect of low $\mathrm{pH}$ concentrations on the stability of MCs.

For MC-LR, equilibrium was achieved after approximately 2 $\mathrm{h}(\mathrm{pH} \mathrm{5-11)}$ for all three size ranges investigated. After an initial decrease, concentrations remained stable with little to no additional adsorption occurring onto any of the microplastics of any size. At $\mathrm{pH} 2$, equilibrium was only achieved for the large- and medium-sized particles of PS. For all four plastics, the greatest adsorption of MC-LR was observed at $\mathrm{pH} 2$ for the smallest size with the highest adsorption occurring with $\mathrm{PE}$ $(\sim 21 \%$ at $\mathrm{pH} 2, p$ value $=0.02)$ and the least with PET $(\sim 1 \%$ at $\mathrm{pH} 9, p$ value $=0.15)$. At $\mathrm{pH} 2$, the initial concentration rapidly declined over the first $6 \mathrm{~h}$, and this loss is likely caused by a combination of the acidic conditions (decline is mirrored in the control samples-Figure 3) and adsorption to the microplastic particles as the decrease is dependent on the type of the microplastic. For PE and PS, a 20\% concentration decrease was observed (compared to $10 \%$ in the control); for PVC, the decrease was $17 \%$ and for PET $13 \%$, showing greater adsorption to PE and PS.

Adsorption of MC-LF was observed for all four types of plastic with equilibrium achieved by $48 \mathrm{~h}$ for most of the large- 


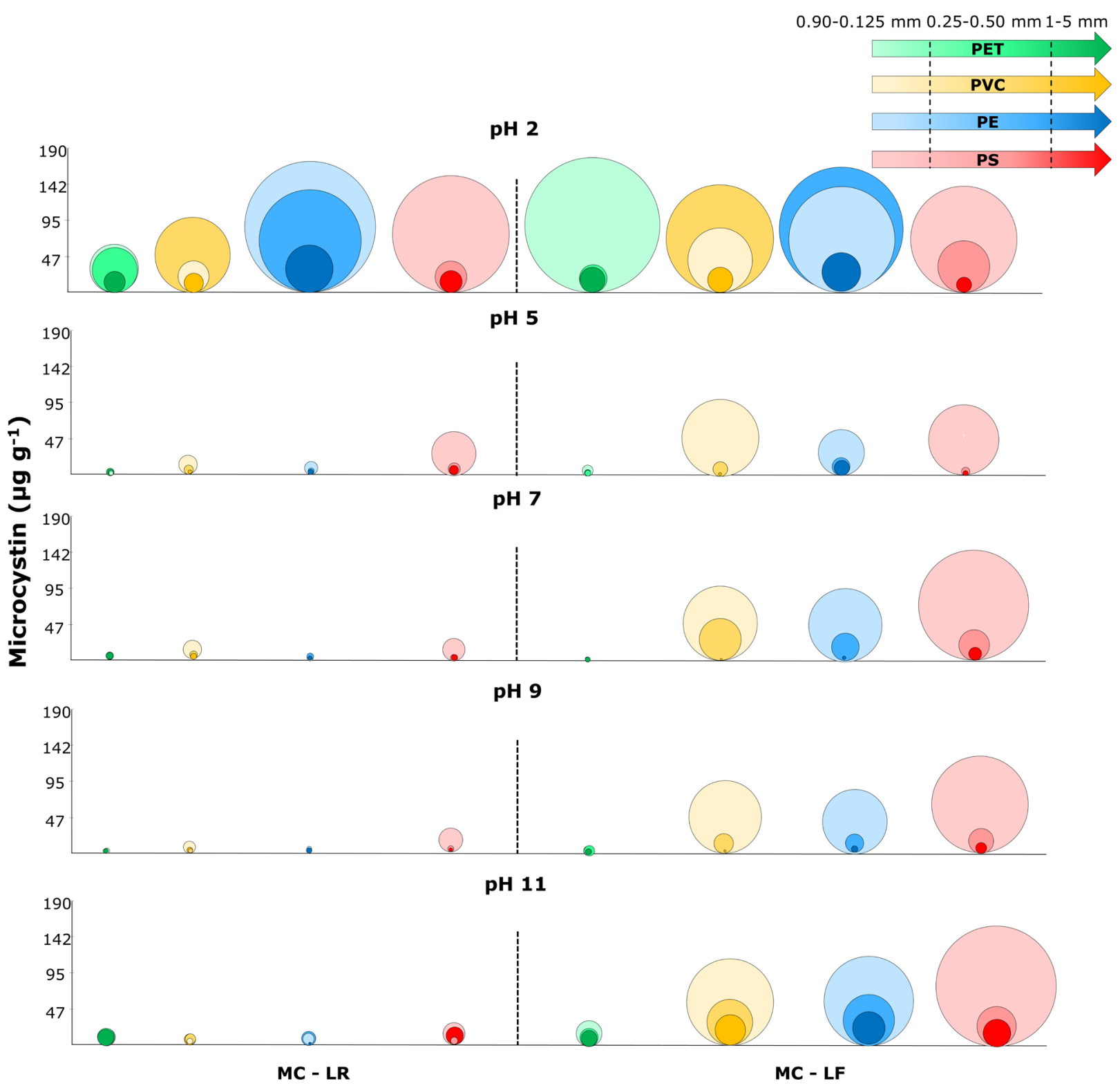

Figure 4. Effect of particle size and $\mathrm{pH}$ on the amount of MC-LR and MC-LF adsorbed onto four different microplastics (green: PET, yellow: PVC, blue: PE, and red: PS) (Test conditions: $10 \mathrm{~g} \mathrm{~L}^{-1}$ plastics, $5 \mu \mathrm{g} \mathrm{mL}^{-1} \mathrm{MCs}, 48 \mathrm{~h}$ agitation time, and $25{ }^{\circ} \mathrm{C}$ ). $\% \mathrm{RSD} \leq 10 \%, n=3$.

sized plastics (PE, PET, and PVC), for some of the mediumsized plastics (PVC and PE), and none for any of the smallsized plastic particles. The highest degree of adsorption was observed for the small particle sizes for all plastics at all $\mathrm{pH}$ values investigated. Most adsorption occurred onto PS ( $\sim 60 \%$ at $\mathrm{pH} 7$ when adjusted with the control) and the least onto PET $(\sim 10 \%$ at $\mathrm{pH} 5-11)$. As was observed for MC-LR at $\mathrm{pH}$ 2 , there was a rapid initial decrease of the toxin concentration in the first $6 \mathrm{~h}$ of the experiment. Most adsorption in this initial phase occurred onto PE (83\%) and PS (85\%) compared to the control (43\%), PVC (76\%), and PET (65\%), which also showed marked decreases in toxin concentration. With the exception of PET, all microplastic types showed significant differences for the MC-LF concentration at $\mathrm{pH} 2$ compared with the control after $48 \mathrm{~h}$ contact. The adsorption of MC-LF follows a similar pattern (rapid initial decrease in toxin concentration followed by a slower decrease) across the other $\mathrm{pH}$ concentrations investigated.
During cyanobacterial bloom events, $\mathrm{pH}$ in the surrounding water frequently increases to above $\mathrm{pH} 9 .{ }^{32}$ Thus, when focusing on what could be considered the most environmentally relevant $\mathrm{pH}$ concentrations of $\mathrm{pH} 5-9$, markedly more MC-LF than MC-LR is adsorbed onto microplastic particles. This becomes particularly apparent when considering the total amounts of MC-LR and MC-LF adsorbed over $48 \mathrm{~h}$ (Figure 4).

Across all pH levels, particle sizes, and types of microplastics, more MC-LF than MC-LR was adsorbed in the environmentally relevant range of $\mathrm{pH} 5-9$. On average, $130 \mu \mathrm{g} \mathrm{g}^{-1}$ MC-LF adsorbed onto the smallest particle size of PS, with 89 $\mu \mathrm{g} \mathrm{g}^{-1}$ MC-LF adsorbed to PE, $99 \mu \mathrm{g} \mathrm{g}^{-1}$ MC-LF adsorbed onto PVC, and $12 \mu \mathrm{g} \mathrm{g}^{-1} \mathrm{MC}-\mathrm{LF}$ adsorbed onto PET, with maximum adsorption of MC-LF of $156 \mu \mathrm{g} \mathrm{g}^{-1}$ achieved with PS. The maximum adsorption of MC-LR in the environmentally important range ( $\mathrm{pH}$ 5-9) was achieved with PS at $\mathrm{pH} 5\left(56 \mu \mathrm{g} \mathrm{g}^{-1}\right)$ and average adsorption of MC-LR was achieved with PS of $28 \mu \mathrm{g} \mathrm{g}^{-1}$, PE of $8 \mu \mathrm{g} \mathrm{g}^{-1}$, PVC of $14 \mu \mathrm{g}$ 
$\mathrm{g}^{-1}$, and PET of $6 \mu \mathrm{g} \mathrm{g}^{-1}$. From these results, it is apparent that the hydrophobicity, due to variable amino acid composition of the MC congener, strongly determines the amount of adsorption. ${ }^{17}$ In the current study, MC-LR and MC-LF differ in the fact that the arginine (R) in MC-LR is replaced with the more hydrophobic phenylalanine (F) in MC-LF. Therefore, as would be expected, MC-LF adsorbs more readily to the microplastic particles than MC-LR (Table 1 and Figures 1 and

Table 1. Comparison of Maximum MC-LR and MC-LF Adsorption onto Four Types of Microplastics ${ }^{a}$

\begin{tabular}{|c|c|c|c|c|}
\hline plastic & $\begin{array}{l}\text { maximum MC-LR } \\
\text { adsorption }(\mu \mathrm{g} \\
\left.\mathrm{g}^{-1}\right)\end{array}$ & $\begin{array}{c}\underset{\left.\mathrm{g}^{-1}\right)}{\operatorname{maximum} \text { MC-LF }} \\
\text { adsorption }(\mu \mathrm{g}\end{array}$ & ASCR & $\begin{array}{c}T_{g} \\
\left({ }^{\circ} \mathrm{C}\right)\end{array}$ \\
\hline $\begin{array}{l}\text { polyethylene } \\
\text { terephthalate } \\
\text { (PET) }\end{array}$ & 0.00 & 0.00 & 4 & 69 \\
\hline $\begin{array}{l}\text { polyethylene } \\
\text { (PE) }\end{array}$ & 0.89 & 76.64 & 1.7 & -125 \\
\hline $\begin{array}{l}\text { polyvinyl } \\
\text { chloride } \\
\text { (PVC) }\end{array}$ & 11.64 & 81.22 & 2.7 & 81 \\
\hline polystyrene (PS) & 22.10 & 119.54 & 1.8 & 100 \\
\hline \multicolumn{5}{|c|}{$\begin{array}{l}{ }^{a} \text { Experimental conditions: } 10 \mathrm{~g} \mathrm{~L}^{-1} \text { plastics, } 5 \mu \mathrm{g} \mathrm{mL}^{-1} \mathrm{MCs}, \mathrm{pH} 7 \text {, } \\
\text { particle size } 0.009-0.125 \mathrm{~mm}, 48 \mathrm{~h} \text {, and } 25^{\circ} \mathrm{C}^{\circ} \text {. ASCR }{ }^{44} \text { is reported in } \\
\text { the literature studies ( } n=12 \text { studies). For ASCR, a score of } 1 \\
\text { indicates the highest sorption capacity and increasing values indicate } \\
\text { types of plastics that exhibit lower sorption capacities as reported in } \\
\text { the } T_{\mathrm{g}} \text { of the polymers used in the current study, }{ }^{42} \text { giving an } \\
\text { indication of the prevalence of amorphous or glassy regions of a given } \\
\text { polymer. }\end{array}$} \\
\hline
\end{tabular}

2). Connected to the hydrophobicity of the sorbent, the $\mathrm{pH}$ of the surrounding matrix will affect the behavior of the MCs. As de Maagd et al. ${ }^{33}$ and McCord et al. ${ }^{34}$ have demonstrated, the hydrophobicity of MCs, expressed as the $\mathrm{pH}$-dependent octanol-water partitioning coefficient $\left(D_{\mathrm{OW}}\right)$, changes as the $\mathrm{pH}$ of the test matrix is altered. As the $\mathrm{pH}$ decreases, the $\log _{10}\left(D_{\mathrm{OW}}\right)$ as a function of the hydrophobicity increases, increasing the likelihood of the MC analogue to adsorb onto the microplastic. The $\log _{10}\left(D_{\mathrm{OW}}\right)$ of MC-LR increases from $-1.2(\mathrm{pH} 7)$ to $1.67(\mathrm{pH} 2)$, whereas the $\log _{10}\left(D_{\mathrm{OW}}\right)$ of MCLF increases from $0.06(\mathrm{pH} 7)$ to $2.75(\mathrm{pH} \mathrm{2}){ }^{33,34}$ Increasing adsorption with decreasing surrounding $\mathrm{pH}$ was also observed in this investigation (Figures 2 and 3) with maximum adsorption for both MC-LR (small-sized PE: $181.6 \mu \mathrm{g} \mathrm{g}^{-1}$ ) and MC-LF (small-sized PET: $187.5 \mu \mathrm{g} \mathrm{g}^{-1}$ ) occurring at $\mathrm{pH}$ 2. Altaner et al. ${ }^{35}$ also found a correlation between the $\mathrm{pH}$ of an $\mathrm{MC}$-containing solution and the amount of adsorption onto polypropylene (PP) laboratory pipette tips, observed after repeated use (eight times) of the tip. The more acidic the solution, the more likely MCs adsorbed to the PP pipette tips, similar to the observations made for the microplastics studied in the current investigation. Altaner et al.'s ${ }^{35}$ observation is explained with the fact that at low $\mathrm{pH}$, most MCs tend to be positively charged due to carboxyl and guanidine moieties being protonated; ${ }^{33,34,36,37}$ while the surface of $\mathrm{PE}$, for example, is negatively charged due to the dissociation of carboxyl groups as part of oxidation processes during polymerization. ${ }^{38}$ Similar observations were made by Hyenstrand et al. ${ }^{37}$ when they tested adsorption of MC-LR onto laboratory PP tips. According to Kamp et al. ${ }^{39}$ the change of surface charge is an important factor affecting the adsorption potential of contaminants on microplastics. The plastics investigated showed a negatively charged surface under all $\mathrm{pH}$ values measured (Table S3). Although the surface charge of the microplastics changed under different $\mathrm{pH}$ conditions, no correlation between the surface charge of plastics and the adsorption behavior of MC-LR and MC-LF was apparent. In the $\mathrm{pH}$ range tested in their study $(\mathrm{pH} 6-10), \mathrm{pH}$ did not markedly affect the adsorption behavior, which correlates to the observations made for the microplastics investigated in the current study (albeit both studies are not directly comparable). Observations made in the current study are further corroborated by a study testing different materials for MC sampling in which Kamp et al. ${ }^{39}$ found that MC-LF more readily adsorbed onto bottles made from a range of plastics (PE, PS, PP, polyethylene terephthalate glycol, and polycarbonate) in drinking water compared to MC-LR at near neutral $\mathrm{pH}$. After $48 \mathrm{~h}$ in the study by Hüffer and Hofmann, ${ }^{40}$ MC-LR adsorption onto PS and PE occurred to a similar degree ( $<10 \%$ adsorption), while for MC-LF, less adsorption occurred ( $\sim 20 \%$ adsorption) compared with small-sized microplastics in the current study (PS $\sim 63 \%$ adsorption and PE $\sim 43 \%$ adsorption). Compared to large-sized microplastic particles, greater adsorption was observed by Hüffer and Hofmann, ${ }^{40}$ since, in the current study, no adsorption occurred on any of the plastics of size >1-5 mm. However, our investigation and the study by Kamp et al. ${ }^{39}$ are again not directly comparable as there were marked differences in the study design (size of the exposed surface, agitation, and temperature during storage).

While in the majority of cases the highest degree of adsorption was observed for the small particle size, this was not true in all instances (e.g., maximum adsorption of MC-LR onto PVC at $\mathrm{pH} 2$ was observed for the medium-sized particles, Figure 3). As partitioning of organic compounds onto microplastics is a surface process, logic would dictate that the smaller the particle, the higher the potential adsorption that can be achieved. This was largely observed in the present study; however, Hüffer and Hofmann ${ }^{40}$ determined that sorption of organic compounds to microplastic particles in aqueous solutions did not exclusively occur according to the particle size as their model sorbents (seven hydrophobic aromatic and nonaromatic hydrocarbons) preferably adsorbed to the largest particle size of PS in their study. Hydrophobicity of the sorbent and $\pi-\pi$ interactions between the PS and the model sorbents were proposed as potential explanations for this observation. $\mathrm{Hu}$ et al., ${ }^{41}$ however, determined increased adsorption as a function of particle size. Their ${ }^{41}$ findings are however difficult to compare to the current study or to the study by Hüffer and Hofmann ${ }^{40}$ as $\mathrm{Hu}$ et al. ${ }^{41}$ investigated the adsorption of lubrication oil on micro- and nanoparticulate plastic particles. $\mathrm{Hu}$ et $\mathrm{al}^{41}$ did not find a significant impact of $\mathrm{pH}$ on the partitioning behavior of lubrication oil to either type of microplastic tested (PE and PS), illustrating that in the case of MCs, $\mathrm{pH}$ influences the sorbate (MCs) more than the sorbent (microplastics).

As established in the current study, the chemical properties of the adsorbent and the particle size of the receiving material critically affect the adsorption of MCs onto microplastic particles. The type of microplastics showed a strong correlation $\left(R^{2}>0.9\right)$ regarding adsorption of MC-LR and MC-LF. A further factor is the chemical composition and surface morphology of this receiving material, specifically, in the case of microplastics, whether the surface of the constituent polymer is glassy or amorphous. ${ }^{42}$ By far, most adsorption 


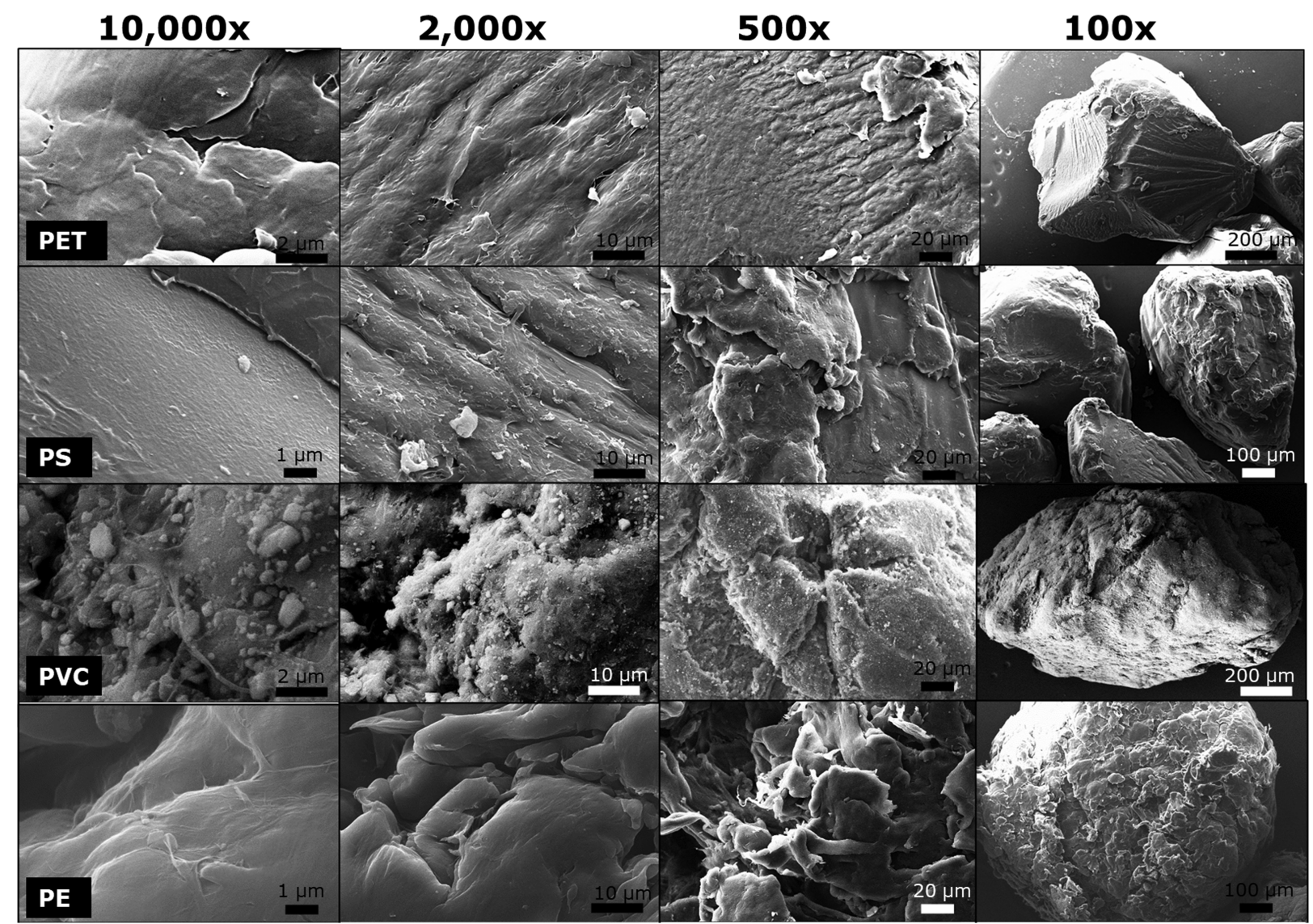

Figure 5. Scanning electron microscope (SEM) imaging of the plastics utilized in the current study clearly displaying the surface morphology of each type. For each type of plastic, a particle size of $1-5 \mathrm{~mm}$ was investigated.

occurs on the amorphous regions of the surface. The glass transition temperature $\left(T_{\mathrm{g}}\right)$ of a polymer is a measure of whether a polymer is considered rubber-like or glass-like. If the ambient temperature is higher than the $T_{\mathrm{g}}$ of a given polymer, it is considered rubber-like at that temperature. If the ambient temperature is lower than the $T_{\mathrm{g}}$ of a given polymer, it is considered glass-like. For example, under the experimental conditions of the current study $\left(25^{\circ} \mathrm{C}\right)$, only PE would be considered rubber-like (Table 1). For the other three microplastics, ambient temperature was $<T_{\mathrm{g}}$; thus, PS, PET, and PVC would be considered glass-like. Guo et al. ${ }^{43}$ found that by decreasing the glassiness and increasing the abundance of amorphous sites on PS, the sorption capacity for organic compounds could be increased, confirming that glassiness plays an important part in the reduced partitioning of organic compounds onto microplastics. In a survey of 12 published studies, Alimi et al. ${ }^{44}$ have created average sorption capacity ranking (ASCR; from 1 = highest sorption potential to $>1$ decreasing sorption potential) for key plastics.

The results of the current investigation follow the proposed ASCR (Table 1), especially for MC-LF that showed a strong negative correlation $\left(R^{2}>-0.8\right)$ between the sorption capacity ranking and the adsorption on microplastics. For PET, with an ASCR score of 4, almost no adsorption of either MC analogue could be detected, whereas PS, which has a comparatively low ASCR score of 1.8 , showed the greatest adsorption potential for both MC analogues investigated. Despite having a higher ASCR score (2.7 compared to 1.7) than PE, PVC showed similar or higher adsorption of MCs across all samples evaluated. While the ASCR score is derived from a number of studies, there are exceptions for each of the plastics where they display a higher or a lower adsorption capacity than would be expected from their ASCR score and glassiness as a function of $T_{\mathrm{g}}$. These exceptions are explained by the individual chemistry of the polymer and the specific interaction with the chemistry of sorbate as well as the surface morphology of the microplastic particle. ${ }^{44}$ Investigating the surface of the microplastic particles applied in the current study shows that PS, PE, and PET present a comparatively smooth surface, while PVC presents a pockmarked surface $(10,000 \times$ magnification, Figure 5). Increased adsorption to PVC could thus, in part, be explained by the rougher surface.

At $500 \times$ magnification, it can be observed that all the plastics except PET present a rough morphology with crevasses and ridges, which could further contribute to the increased adsorption of those types of microplastic compared to PET, which presents a comparatively smooth surface. The effect of surface morphology on adsorption was also observed by Fotopoulou and Karapanagioti ${ }^{45}$ when comparing the surface morphologies of virgin and eroded PE, PP, and PVC. Comparing the SEM images of the surface morphology in our study and the study by Fotopoulou and Karapanagioti, ${ }^{45}$ similarities between our microplastic and the eroded plastic in their studies are apparent.

The overriding parameter for MC adsorption onto the selected plastics, however, appears to be the hydrophobicity of the MC analogue determined by the variable amino acid rather than the type of microplastic (e.g., PVC over PET) and particle size (small over large). However, establishing a clear hierarchical order of factors determining the adsorption of 
MCs onto microplastics is difficult as the effects of MC hydrophobicity, particle size, and $\mathrm{pH}$ are all interwoven and interdependent representing a multifactorial system. While on the one hand, the surface area-to-volume ratio of the plastic will influence adsorption onto the surface of the microplastic, ${ }^{9}$ on the other hand, the hydrophobicity, that is, the variable amino acid composition of the MC molecule will strongly influence adsorption. Additionally, surface morphology, availability of amorphous regions on the polymers, and $\mathrm{pH}$ concentration will also influence adsorption.

The results of the current study have demonstrated that under all conditions investigated, MC-LF is more likely to adsorb onto microplastic particles compared to MC-LR. This finding should be viewed in an environmental context: MC-LR is the most frequently studied $\mathrm{MC}$ congener and most countries' legislature relating to maximal allowable levels of MCs in, for example, drinking water are often maybe based solely on MC-LR presence or MC-LR toxicity equivalence. However, in recent years, it has repeatedly been demonstrated that MC-LF presents greater toxicity than MC-LR. ${ }^{16,19}$ In light of this, the WHO has recently amended its guidelines for maximum allowable levels of MCs in drinking water to use the total $\mathrm{MC}$ concentration rather than toxicity equivalence. ${ }^{24}$ As demonstrated in the present study, MC-LF preferably adsorbed to microplastic particles compared to MC-LR, which is concerning in light of its greater toxicity. The results of the current study demonstrate the limitations of exclusively using MC-LR as a single representative of the wider group of MCs.

Generally, eutrophicated waters, that is, water bodies with a high nutrient load, are preferred habitats of aquatic cyanobacteria. Wastewater treatment plants and effluents are good examples with routine mass occurrences (blooms) of cyanobacteria. $^{46,47}$ Microplastic particles are likely to be encountered in wastewaters, and co-occurrence of microplastic particles and MCs frequently takes place. Having demonstrated the presence of MCs on microplastics (Figure 5) and the load per mass of plastic determined (Figure 3), theoretical exposure of aquatic organisms to $\mathrm{MC}$ on microplastic particles can be calculated as there is a concern that pollutants adsorbed to microplastics could enter the food web. ${ }^{4,6}$ Assuming that all MCs adsorbed onto the microplastic particles will desorb in the gut of biota and all desorbed toxin will be bioavailable, the following worse-case scenario could be imagined: a recent study by Canniff and Hoang ${ }^{3}$ has demonstrated that the water flea Daphnia magna can consume microplastic particles in a size range of $63-75 \mu \mathrm{m}$. The smallest particle size investigated in the current study is in the range of 90 to $125 \mu \mathrm{m}$. While this is larger than the particles used in the Canniff and Hoang ${ }^{3}$ study, it was used to predict a theoretical MC uptake by Daphnia sp. by means of feeding on MC-laden particles. Canniff and Hoang ${ }^{3}$ demonstrated that up to 15 particles were ingested by individual Daphnia magna in 21 days of exposure (with the first particles being ingested within $6 \mathrm{~h}$ ); by calculating the amount of the two different MC congeners per plastic particle in the current study (Supporting Information S4), it was possible to predict the MC load per individual Daphnia (Table 2). Correlating this toxin load to the published lethal concentrations of MC-LR for Daphnia demonstrated that the amount of MC-LR would not constitute a lethal dose for Daphnia. However, assuming a similar, or even higher, toxicity of MC-LF compared to MC-LR (as proposed by Faassen and Lürling ${ }^{16}$ ), it could be demonstrated that
Table 2. Predicted MC-LR and MC-LF Amounts per Plastic Particle after $48 \mathrm{~h}$ of Exposure, Hypothetical Amounts of MCs Ingested by Daphnia sp., and Lethal Doses $\left(\mathrm{LD}_{50}\right)$ of MC-LR in Daphnia sp. ${ }^{a}$

$\begin{array}{lcccc}\text { toxin }(\mu \mathrm{g} & \begin{array}{c}\text { toxin } \\ \left.\mathrm{g}^{-1}\right) \text { on } \\ \text { plastic after } \\ 48 \mathrm{~h}\end{array} & \begin{array}{c}\text { theoretical toxin } \\ \text { amount }(\mathrm{pg}) \\ \text { particle } \\ \text { ingested by } \\ \text { daphnids }\end{array} & \begin{array}{c}\text { lethal ingested } \\ \text { dose of MC (pg) } \\ \text { for daphnids }\end{array} \\ \begin{array}{l}\text { MC-LR } \\ \text { PET }\end{array} & 0 & 0 & 0 & 510-915 \\ \text { PVC } & 13.85 & 12.4 & 186 & \\ \text { PE } & 1.06 & 0.64 & 96 & 510-915^{d} \\ \text { PS } & 26.31 & 23.6 & 354 & \\ \text { MC-LF } & & & & \\ \text { PET } & 0 & 0 & 0 & \\ \text { PVC } & 96.69 & 86.7 & 1300 & \\ \text { PE } & 91.23 & 55.1 & 826 & \\ \text { PS } & 142.31 & 127 & 1910 & \end{array}$

${ }^{a}$ Experimental conditions: $10 \mathrm{~g} \mathrm{~L}^{-1}$ plastics, $5 \mu \mathrm{g} \mathrm{mL}^{-1} \mathrm{MCs}$, and horizontal agitation in the dark at $\mathrm{pH} 7{ }^{b}$ Derived from the study of Canniff and Hoang ${ }^{3}$ which observed uptake of up to 15 microplastic particles per Daphnia sp. individual in a feeding study. ${ }^{c}$ Derived from the study of Rohrlack et al. ${ }^{48}$ which state MC-LR toxicity as 10.2 to $18.3 \mathrm{ng} \mathrm{mg}^{-1}$ wet weight in Daphnia sp. and from the study of Badouin and Ravera ${ }^{49}$ stating the dry weight of individual mature Daphnia sp. as $21.33 \mu \mathrm{g}$ wet weight, which was assumed to be $200 \%$ of the dry weight. ${ }^{d}$ Assuming similar toxicity to MC-LR as proposed by Faassen and Lürling. ${ }^{16}$

ingestion of 15 MC-LF-laden particles would be lethal if desorbed from the microplastic (with the caveat that the reported lethal concentration does not directly correspond to the lethal ingested dose). While this prediction is based on a number of assumptions and data based on different species of Daphnia, it nonetheless demonstrates the potential of biologically relevant amounts of MCs entering the food web by means of toxin-laden microplastic ingestion.

In a feeding study, Christoffersen ${ }^{50}$ demonstrated that the arctic tadpole shrimp (Lepidurus arcticus (L. arcticus)) was capable of predating on a Daphnia species. Larger L. arcticus was shown to have consumed 5 to 15 Daphnia. Extrapolating from the data in Table 2, this would represent concentrations of 1.77 to $5.31 \mathrm{ng}$ and 9.55 to $28.65 \mathrm{ng}$ of MC-LR and MC-LF, respectively (adsorbed to PS particles). While there are no toxicity data of the effect of MCs on tadpole shrimp, this example demonstrates the theoretical accumulation of toxin in the food web, with increasing trophic level, with plastics as a vector.

\section{IMPLICATIONS}

The current study has, for the first time, demonstrated that at least three types of microplastics (PVC, PE, and PS) can act as vectors for MCs; an almost 40-fold concentration compared to the dissolved concentration was observed for some MC congener-microplastic combinations (e.g., MC-LF + PS). Adsorption of MCs to microplastic particles is a multifactor process. The current study demonstrated that the particle size of the microplastics, $\mathrm{pH}$ conditions, the type of polymer, and the $\mathrm{MC}$ congener affect adsorption. Even under environmentally relevant $\mathrm{pH}$ conditions $(\mathrm{pH} 7), \mathrm{MC}-\mathrm{LF}$ adsorbed to microplastic particles. A theoretical worst-case scenario demonstrated that the amount of MC adsorbed onto certain types of plastics, if desorbed, would constitute a lethal dose to 
daphnids. Furthermore, this study highlights that adopting MC-LR as a model for all MCs is a poor choice as the chemical diversity created by the two variable amino acids can lead to widely varying adsorption behaviors. This was demonstrated by the significantly greater adsorption of MC-LF compared to MC-LR under the same experimental conditions. Microplastics could act as a vector for MCs, highlighting an, as of yet, unexplored pathway for cyanobacterial toxins to enter the food web.

\section{ASSOCIATED CONTENT}

\section{SI Supporting Information}

The Supporting Information is available free of charge at https://pubs.acs.org/doi/10.1021/acs.est.1c05796.

Chemical structures of the four plastic monomers; list of chemicals, materials, devices, and auxiliaries; 3D surface MALDI imaging of MC-LF bound to PET microplastic particles; calculations for prediction of amount of toxin per individual plastic particle; evaluation of the electrostatic charge of each type of microplastic under five $\mathrm{pH}$ conditions; and statistical analysis (PDF)

\section{AUTHOR INFORMATION}

\section{Corresponding Author}

Carlos J. Pestana - School of Pharmacy and Life Sciences, Robert Gordon University, Aberdeen AB10 7GJ, U.K.; ○ orcid.org/0000-0002-5619-6968; Phone: +44 1224 262847; Email: c.pestana@rgu.ac.uk

\section{Authors}

Diana S. Moura - School of Pharmacy and Life Sciences, Robert Gordon University, Aberdeen AB10 7GJ, U.K.; Department of Hydraulic and Environmental Engineering, Federal University of Ceará, Fortaleza, Ceará 60440-593, Brazil

José Capelo-Neto - Department of Hydraulic and Environmental Engineering, Federal University of Ceará, Fortaleza, Ceará 60440-593, Brazil

Christine Edwards - School of Pharmacy and Life Sciences, Robert Gordon University, Aberdeen AB10 7GJ, U.K.

Domenic Dreisbach - Institute of Inorganic and Analytical Chemistry, Justus Liebig University, Giessen D-35392, Germany

Bernhard Spengler - Institute of Inorganic and Analytical Chemistry, Justus Liebig University, Giessen D-35392, Germany; @ orcid.org/0000-0003-0179-5653

Linda A. Lawton - School of Pharmacy and Life Sciences, Robert Gordon University, Aberdeen AB10 7GJ, U.K.

Complete contact information is available at: https://pubs.acs.org/10.1021/acs.est.1c05796

\section{Notes}

The authors declare the following competing financial interest(s): B.S. is a consultant and D.D. is a part-time employee of TransMIT GmbH (Giessen, Germany).

\section{ACKNOWLEDGMENTS}

The authors would like to thank the Engineering and Physical Science Research Council UK [EP/P029280/1] and the Newton Mobility Grant [NMG $\backslash \mathrm{R} 2 \backslash 170134]$ for funding this research project. In addition, the authors would like to thank Len Montgomery for proof-reading the manuscript and Iain
Tough for the SEM imaging. Furthermore, technical support provided by TransMIT GmbH and by Thermo Fisher Scientific (Bremen) $\mathrm{GmbH}$ and financial support by the Deutsche Forschungsgemeinschaft DFG [Sp314/23-1] are gratefully acknowledged.

\section{REFERENCES}

(1) van Wezel, A.; Caris, I.; Kools, S. A. E. Release of Primary Microplastics from Consumer Products to Wastewater in the Netherlands. Environ. Toxicol. Chem. 2016, 35, 1627-1631.

(2) Plastics Europe. Plastics - the Facts 2017; 2017.

(3) Canniff, P. M.; Hoang, T. C. Microplastic Ingestion by Daphnia Magna and Its Enhancement on Algal Growth. Sci. Total Environ. 2018, 633, 500-507.

(4) Bakir, A.; O'Connor, I. A.; Rowland, S. J.; Hendriks, A. J.; Thompson, R. C. Relative Importance of Microplastics as a Pathway for the Transfer of Hydrophobic Organic Chemicals to Marine Life. Environ. Pollut. 2016, 219, 56-65.

(5) Eerkes-Medrano, D.; Thompson, R. C.; Aldridge, D. C. Microplastics in Freshwater Systems: A Review of the Emerging Threats, Identification of Knowledge Gaps and Prioritisation of Research Needs. Water Res. 2015, 75, 63-82.

(6) Teuten, E. L.; Saquing, J. M.; Knappe, D. R. U.; Barlaz, M. A.; Jonsson, S.; Björn, A.; Rowland, S. J.; Thompson, R. C.; Galloway, T. S.; Yamashita, R.; Ochi, D.; Watanuki, Y.; Moore, C.; Viet, P. H.; Tana, T. S.; Prudente, M.; Boonyatumanond, R.; Zakaria, M. P.; Akkhavong, K.; Ogata, Y.; Hirai, H.; Iwasa, S.; Mizukawa, K.; Hagino, Y.; Imamura, A.; Saha, M.; Takada, H. Transport and Release of Chemicals from Plastics to the Environment and to Wildlife. Philos. Trans. R. Soc. B Biol. Sci. 2009, 364, 2027-2045.

(7) Li, J.; Liu, H.; Paul Chen, J. Microplastics in Freshwater Systems: A Review on Occurrence, Environmental Effects, and Methods for Microplastics Detection. Water Res. 2018, 137, 362-374.

(8) Anderson, J. C.; Park, B. J.; Palace, V. P. Microplastics in Aquatic Environments: Implications for Canadian Ecosystems. Environ. Pollut. 2016, 218, 269-280.

(9) Crawford, C. B.; Quinn, B. Microplastic Pollutants; Elsevier Ltd: Amsterdam, 2017, 131-154.

(10) Massos, A.; Turner, A. Cadmium, Lead and Bromine in Beached Microplastics. Environ. Pollut. 2017, 227, 139-145.

(11) Rochman, C. M.; Hoh, E.; Hentschel, B. T.; Kaye, S. LongTerm Field Measurement of Sorption of Organic Contaminants to Five Types of Plastic Pellets: Implications for Plastic Marine Debris. Environ. Sci. Technol. 2013, 47, 1646-1654.

(12) Bláha, L.; Babica, P.; Maršálek, B. Toxins Produced in Cyanobacterial Water Blooms - Toxicity and Risks. Interdiscip. Toxicol. 2009, 2, 36-41.

(13) Visser, P. M.; Verspagen, J. M. H.; Sandrini, G.; Stal, L. J.; Matthijs, H. C. P.; Davis, T. W.; Paerl, H. W.; Huisman, J. How Rising $\mathrm{CO} 2$ and Global Warming May Stimulate Harmful Cyanobacterial Blooms. Harmful Algae 2016, 54, 145-159.

(14) Paerl, H. W.; Paul, V. J. Climate Change: Links to Global Expansion of Harmful Cyanobacteria. Water Res. 2012, 46, 13491363.

(15) Spoof, L.; Catherine, A. Appendix 3, Tables of Microcystins and Nodularins. In Handbook of Cyanobacterial Monitoring and Cyanotoxin Analysis; Meriluoto, J., Spoof, L., Codd, G. A., Eds.; John Wiley \& Sons: Chichester, UK, 2017; 526-537, DOI: 10.1002/ 9781119068761.app3.

(16) Faassen, E. J.; Lürling, M. Occurrence of the Microcystins MCLW and MC-LF in Dutch Surface Waters and Their Contribution to Total Microcystin Toxicity. Mar. Drugs 2013, 11, 2643-2654.

(17) Vesterkvist, P. S. M.; Misiorek, J. O.; Spoof, L. E. M.; Toivola, D. M.; Meriluoto, J. A. O. Comparative Cellular Toxicity of Hydrophilic and Hydrophobic Microcystins on Caco-2 Cells. Toxins 2012, 4, 1008-1023.

(18) Fischer, A.; Hoeger, S. J.; Stemmer, K.; Feurstein, D. J.; Knobeloch, D.; Nussler, A.; Dietrich, D. R. The Role of Organic 
Anion Transporting Polypeptides (OATPs/SLCOs) in the Toxicity of Different Microcystin Congeners in Vitro: A Comparison of Primary Human Hepatocytes and OATP-Transfected HEK293 Cells. Toxicol. Appl. Pharmacol. 2010, 245, 9-20.

(19) Feurstein, D.; Holst, K.; Fischer, A.; Dietrich, D. R. OatpAssociated Uptake and Toxicity of Microcystins in Primary Murine Whole Brain Cells. Toxicol. Appl. Pharmacol. 2009, 234, 247-255.

(20) Vesterkvist, P. S. M.; Meriluoto, J. A. O. Interaction between Microcystins of Different Hydrophobicities and Lipid Monolayers. Toxicon 2003, 41, 349-355.

(21) Royal Society of Chemistry. Microcystin-LR structure.

(22) Royal Society of Chemistry. Microcystin-LF structure.

(23) WHO. Guidelines for Drinking-Water Quality; WHO Press: Geneva, Switzerland, 2008.

(24) WHO, Cyanobacterial Toxins : Microcystins. Background Document for Drinking-Water Quality and Guidelines for Safe Recreational Water Environments; W. H. O. Geneva, 2020.

(25) Akkanen, J.; Kukkonen, J. V. K. Biotransformation and Bioconcentration of Pyrene in Daphnia Magna. Aquat. Toxicol. 2003, 64, 53-61.

(26) Kompauer, M.; Heiles, S.; Spengler, B. Autofocusing MALDI Mass Spectrometry Imaging of Tissue Sections and 3D Chemical Topography of Nonflat Surfaces. Nat. Methods 2017, 14, 1156-1158. (27) Paschke, C.; Leisner, A.; Hester, A.; Maass, K.; Guenther, S.; Bouschen, W.; Spengler, B. Mirion - A Software Package for Automatic Processing of Mass Spectrometric Images. J. Am. Soc. Mass Spectrom. 2013, 24, 1296-1306.

(28) Dris, R.; Imhof, H.; Sanchez, W.; Gasperi, J.; Galgani, F.; Tassin, B.; Laforsch, C. Beyond the Ocean: Contamination of Freshwater Ecosystems with (Micro-)Plastic Particles. Environ. Chem. 2015, 12, 539.

(29) Wang, J.; Tan, Z.; Peng, J.; Qiu, Q.; Li, M. The Behaviors of Microplastics in the Marine Environment. Mar. Environ. Res. 2016, $113,7-17$.

(30) Wang, W.; Wang, J. Comparative Evaluation of Sorption Kinetics and Isotherms of Pyrene onto Microplastics. Chemosphere 2018, 193, 567-573.

(31) Harada, K.; Tsuji, K.; Watanabe, M. F.; Kondo, F. Stability of Microcystins from Cyanobacteria - III. Effect of $\mathrm{PH}$ and Temperature. Phycologia 1996, 35, 83-88.

(32) Wilhelm, S. W.; Bullerjahn, G. S.; McKay, R. M. L. The Complicated and Confusing Ecology of Microcystis Blooms. MBio 2020, 11, 1-5.

(33) De Maagd, P. G. J.; Hendriks, A. J.; Seinen, W.; Sijm, D. T. H. M. PH-Dependent Hydrophobicity of the Cyanobacteria Toxin Microcystin-LR. Water Res. 1999, 33, 677-680.

(34) McCord, J.; Lang, J. R.; Hill, D.; Strynar, M.; Chernoff, N. PH Dependent Octanol-Water Partitioning Coefficients of Microcystin Congeners. J. Water Health 2018, 16, 340-345.

(35) Altaner, S.; Puddick, J.; Wood, S. A.; Dietrich, D. R. Adsorption of Ten Microcystin Congeners to Common Laboratory-Ware Is Solvent and Surface Dependent. Toxins 2017, 9, 129.

(36) Liang, G.; Xie, P.; Chen, J.; Yu, T. Comparative Studies on the PH Dependence of DOW of Microcystin-RR and -LR Using LC-MS. Sci. World J. 2011, 11, 20-26.

(37) Hyenstrand, P.; Metcalf, J. S.; Beattie, K. A.; Codd, G. A. Effects of Adsorption to Plastics and Solvent Conditions in the Analysis of the Cyanobacterial Toxin Microcystin-LR by High Performance Liquid Chromatography. Water Res. 2001, 35, 3508-3511.

(38) Beneš, P.; Paulenová, M. Surface Charge and Adsorption Properties of Polyethylene in Aqueous Solutions of Inorganic Electrolytes - II. Radiochemical Investigation. Colloid Polym. Sci. 1974, 252, 472-477.

(39) Kamp, L.; Church, J. L.; Carpino, J.; Faltin-Mara, E.; Rubio, F. The Effects of Water Sample Treatment, Preparation, and Storage Prior to Cyanotoxin Analysis for Cylindrospermopsin, Microcystin and Saxitoxin. Chem.-Biol. Interact. 2016, 246, 45-51.
(40) Hüffer, T.; Hofmann, T. Sorption of Non-Polar Organic Compounds by Micro-Sized Plastic Particles in Aqueous Solution. Environ. Pollut. 2016, 214, 194-201.

(41) Hu, J. Q.; Yang, S. Z.; Guo, L.; Xu, X.; Yao, T.; Xie, F. Microscopic Investigation on the Adsorption of Lubrication Oil on Microplastics. J. Mol. Liq. 2017, 227, 351-355.

(42) Endo, S.; Koelmans, A. A. Sorption of Hydrophobic Organic Compounds to Plastics in the Marine Environment: Equilibrium. In Hazardous Chemicals Associated with Plastics in the Marine Environment; Takada, H., Karapanagioti, H., Eds.; Springer: Switzerland, 2016.

(43) Guo, X.; Wang, X.; Zhou, X.; Kong, X.; Tao, S.; Xing, B. Sorption of Four Hydrophobic Organic Compounds by Three Chemically Distinct Polymers: Role of Chemical and Physical Composition. Environ. Sci. Technol. 2012, 46, 7252-7259.

(44) Alimi, O. S.; Farner Budarz, J.; Hernandez, L. M.; Tufenkji, N. Microplastics and Nanoplastics in Aquatic Environments: Aggregation, Deposition, and Enhanced Contaminant Transport. Environ. Sci. Technol. 2018, 52, 1704-1724.

(45) Fotopoulou, K. N.; Karapanagioti, H. K. Surface Properties of Beached Plastics. Environ. Sci. Pollut. Res. 2015, 22, 11022-11032.

(46) Pestana, C. J.; Hobson, P.; Robertson, P. K. J.; Lawton, L. A.; Newcombe, G. Removal of Microcystins from a Waste Stabilisation Lagoon: Evaluation of a Packed-Bed Continuous Flow TiO2 Reactor. Chemosphere 2020, 245, No. 125575.

(47) Praptiwi, R. A.; Pestana, C. J.; Sawade, E. T.; Swain, N.; Schroeder, G.; Newcombe, G. Treatment Challenge of a Cyanobacterium Romeria Elegans Bloom in a South Australian Wastewater Treatment Plant - a Case Study. Environ. Technol. 2017, 38, 782788.

(48) Rohrlack, T.; Christoffersen, K.; Dittmann, E.; Nogueira, I.; Vasconcelos, V.; Börner, T. Ingestion of Microcystins by Daphnia: Intestinal Uptake and Toxic Effects. Limnol. Oceanogr. 2005, 50, 440448.

(49) Baudouin, M. F.; Ravera, O. Weight, Size, and Chemical Composition of Some Freshwater Zooplankters: Daphnia Hyalina (Leydig). Limnol. Oceanogr. 1972, 17, 645-649.

(50) Christoffersen, K. Predation on Daphnia Pulex by Lepidurus Arcticus. Hydrobiologia 2001, 442, 223-229. 
1 Supporting Information:

2 Potentially poisonous plastic particles: microplastics as vector for cyanobacterial toxins microcystin-LR and -LF

4

5 Carlos J. Pestanaa, Diana S. Mouraa,b, José Capelo-Netob ${ }^{\text {, Christine Edwardsa }}$,

6 Domenic Dreisbachc, Bernhard Spenglerc, Linda A. Lawtona

7

8 a School of Pharmacy and Life Sciences, Robert Gordon University, Aberdeen, UK

9 b Department of Hydraulic and Environmental Engineering, Federal University of

10 Ceará, Fortaleza, Brazil

11 c Institute of Inorganic and Analytical Chemistry, Justus Liebig University,

12 Giessen, Germany

15 The supporting information contains 5 figures, 5 tables, and 2 equations on 14 16 pages. 


\section{Table of contents:}

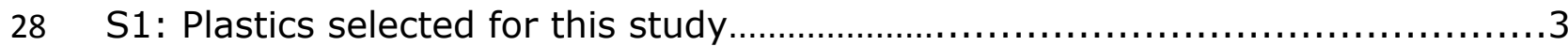

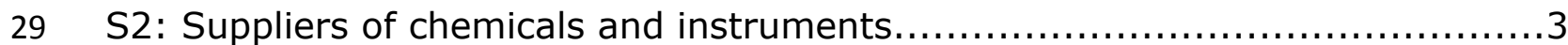

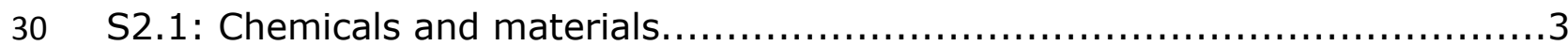

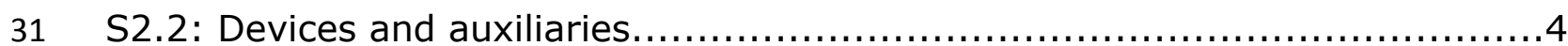

32 S3: 3D-surface MALDI imaging of MC-LF bound to PET microplastic particles

34 S4: Prediction of toxin concentration per particle of plastic.

36 S5: Evaluation of the electrostatic charge of each type of microplastics under

37 five $\mathrm{pH}$ conditions

38 S6: Statistical analysis.

39 S6.1: Significance testing performed using T-test comparing samples with the

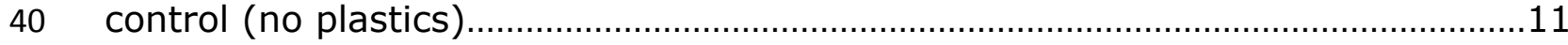

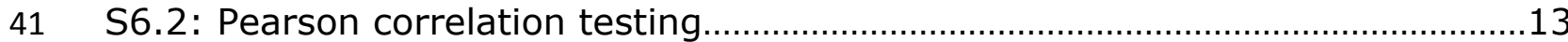

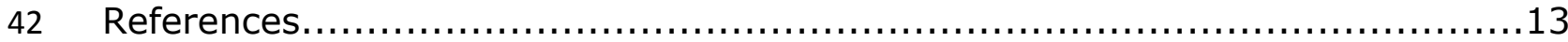




\section{S1 Plastics selected for this study}

57

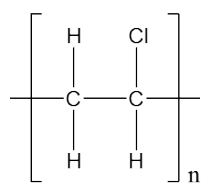

Polyvinyl chloride (PVC)

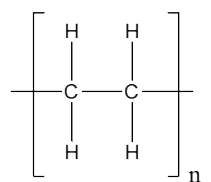

Polyethylene (PE)

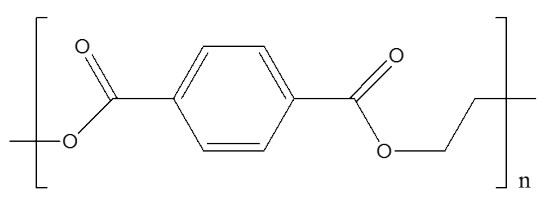

Polyethylene terephthalate (PET)

Figure S1: Chemical structures of plastic monomers selected as sorbents in this study. Representing four of the most commonly encountered plastic pollutants in the environment.

Additionally, the selected plastics present with a chemically diverse set of monomers including aromatic rings (PS and PET) and halogen moieties (PVC) which can affect adsorption behaviour and sorbent-sorbate interaction ${ }^{5}$.

\section{S2: Suppliers of chemicals and instruments}

\section{S2.1 Chemicals and materials}

All organic solvents (methanol and acetonitrile) were purchased from Fisher Scientific (UK) and were of analytical grade. Trifluoroacetic acid (TFA) used as ion pairing agent in high performance liquid chromatography (HPLC) was 
purchased from Fisher Scientific (UK). Microcystin-LR and -LF reference

materials were isolated from laboratory cultures with $>90 \%$ purity. Ultrapure water was produced with an Elga Water Purification System to a resistivity of 18.2 $\mathrm{M} \Omega$. Chemical solutions for the adjustment of the $\mathrm{pH}$ (nitric acid and sodium hydroxide) were purchased from Sigma Aldrich (UK). The chemicals for the preparation of artificial freshwater $\left(\mathrm{CaCl}_{2} \cdot 2 \mathrm{H}_{2} \mathrm{O}, \mathrm{MgSO}_{4} \cdot 2 \mathrm{H}_{2} \mathrm{O}, \mathrm{NaHCO}_{3}\right.$, and $\mathrm{KCl}$ ) were purchased from Fischer Scientific (UK). Polystyrene, polyethylene, and polyethylene terephthalate were received as pellets (3-5 mm diameter), while polyvinyl chloride was received as $1 \mathrm{~m}$ rods ( $5 \mathrm{~mm}$ diameter). All plastics were purchased from Goodfellow (UK). Fourier Transformer Infrared

Spectrophotometry (FT-IR) were used characterised the plastics received to establish the polymer material received (Figure S2). The spectra confirmed the polymer type of the plastics used in the current study.
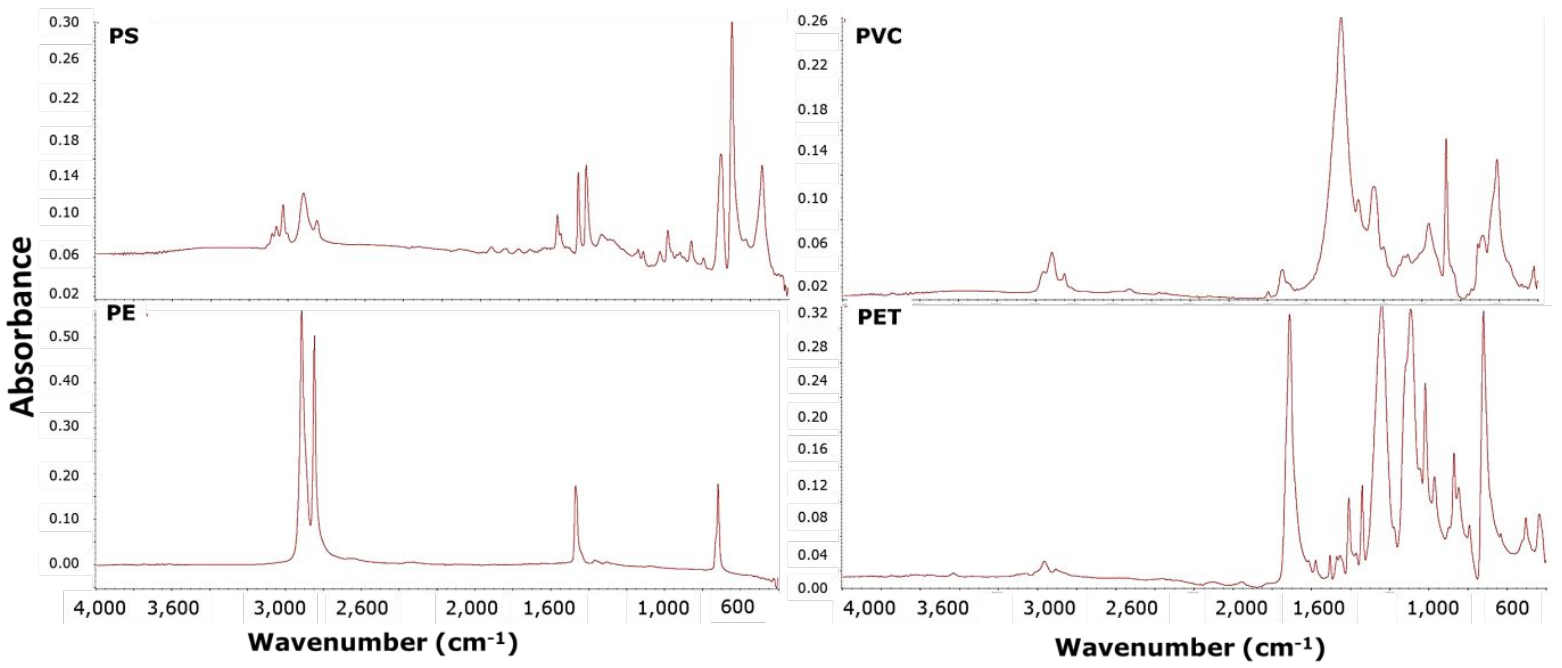

Figure S2: FT-IR spectrum of polystyrene (PS), polyvinyl chloride (PVC), polyethylene $(\mathrm{PE})$, and polyethylene terephthalate (PET).

\section{S2.2 Devices and auxiliaries}

A Nicolet iS10 FT-IR Spectrometer from Thermo Fisher Scientific with OMNIC Spectra Software was used to analyse the material received from GoodFellow, UK. The FT-IR scanning wavenumber was set from 400 to $4000 \mathrm{~cm}^{-1}$. The 
sample was scanned 32 times, the resolution was set at $8 \mathrm{~cm}^{-1}$, no correction was applied.

HPLC analysis was performed by using a Waters 2695 Separation Module. High resolution photodiode array detection was performed with a Waters 2996 Photodiode Array Detector (PDA). Separation of analytes was performed with a Symmetry C18 column $2.1 \mathrm{~mm}$ (inner diameter) x $150 \mathrm{~mm}$ with a $5 \mu \mathrm{m}$ particle size (all Waters, UK). The mobile phases used were ultrapure water and acetonitrile, both $0.05 \%$ TFA. Chromatography was achieved with a linear gradient from 15 to $75 \%$ acetonitrile over 10 minutes, followed by a solvent wash and equilibration. Column temperature was set to $40^{\circ} \mathrm{C}$ and the flowrate applied was $0.3 \mathrm{~mL} \mathrm{~min}{ }^{-1}$. The resolution of the PDA was set to $1.2 \mathrm{~nm}$ and data was acquired over a range of 200 to $400 \mathrm{~nm}$. The limit of quantification achieved by this method was $0.1 \mu \mathrm{g} \mathrm{mL}^{-1}$. The measurement of $\mathrm{pH}$ was performed with a Five Easy pH probe (Mettler Toledo, USA). Experiments were conducted in an incubation chamber with an orbital shaker (Thermofisher MaxQ 6000, UK) at $25^{\circ} \mathrm{C}$ with horizontal agitation at $250 \mathrm{rpm}$. Size reduction of the plastics was achieved in an industrial stainless-steel blender (Waring, USA).

Scanning electron microscopy of the $0.09-0.125 \mathrm{~mm}$ plastic samples was performed on an EVO LS10 (Carl Zeiss Ltd, Germany) scanning electron microscope. Samples were mounted on aluminium stubs with double sides carbon adhesive pads and then sputter coated in a gold and palladium mixture. Scanning electron microscopy was performed under stable pressure, with an acceleration voltage of $25 \mathrm{kV}$ and a working distance of 6.5 to $8 \mathrm{~mm}$. 3D-surface MALDI imaging was performed using an autofocusing AP-SMALDI5 AF high-resolution MALDI imaging ion source (TransMIT GmbH, Germany), operating at atmospheric pressure and coupled to a Q Exactive HF Orbitrap mass 
spectrometer (Thermo Fisher Scientific, Germany). The sample was irradiated with 50 UV-laser pulses $(\lambda=343 \mathrm{~nm}$ ) per pixel at a frequency of $100 \mathrm{~Hz}$. The dedicated autofocusing system enabled keeping the laser focus diameter, fluence and ablation spot size constant across the non-flat sample surface by adjusting the sample stage position according to the sample's height profile for each measurement spot. Samples were scanned with $12 \mu \mathrm{m}$ step size and the target voltage was set to $3 \mathrm{kV}$. The mass spectrometer was operated in positive-ion mode in a mass-to-charge-number $(\mathrm{m} / \mathrm{z})$ range of 350 to 1200 at a mass resolution of 240,000 at $\mathrm{m} / \mathrm{z} 200$. Internal lock-mass calibration was performed by using a signal of a DHB matrix cluster ([5DHB- $\left.\left.4 \mathrm{H}_{2} \mathrm{O}+\mathrm{NH}_{4}\right]^{+}, m / z 716.12461\right)$, resulting in a mass accuracy of better than $2 \mathrm{ppm}$ for the entire image. The ion injection time was set to 500 ms. The S-lens level was set to 100 arbitrary units, and the capillary temperature was $250^{\circ} \mathrm{C}$.

A Malvern Zetasizer Nano-ZS ZEN3600 was used to measure the electrostatic charge of PET, PVC, PE, and PS in the experimental medium under five different pHs. A solution containing $20 \mathrm{~g} \mathrm{~L}^{-1}$ of each plastic in AFW adjusted to $\mathrm{pH} 3, \mathrm{pH} 5$, $\mathrm{pH} 7, \mathrm{pH} 9$, and $\mathrm{pH} 10$ was prepared. The $\mathrm{pH} 2$ and $\mathrm{pH} 11$ were not evaluated due the zeta potential cell compatibility (Malvern Zetasizer cell, DTS1070). Before each analysis, the cell was washed with filtered $(0.22 \mu \mathrm{m})$ methanol followed by filtered $(0.22 \mu \mathrm{m})$ ultra-pure water $(18.2 \mathrm{M} \Omega)$. Later, the solution with microplastics was placed in the zeta cell carefully evaluating the existence of bubbles. Three measurements were performed of each sample.

\section{S3: 3D-surface MALDI imaging of MC-LF bound to polystyrene (PS)} microplastic particles 
149 The optical image of the matrix-covered microplastic surface after analysis is depicted in Figure S3b, demonstrating uniform laser ablation spots throughout

151 the sample height profile (see Figure S3c). PS microplastic samples showed

152 height variations up to $155 \mu \mathrm{m}$ (see Figure S4). To overcome the limitation of non-flat surfaces in microplastic samples, a MALDI imaging ion source with the surface mode").
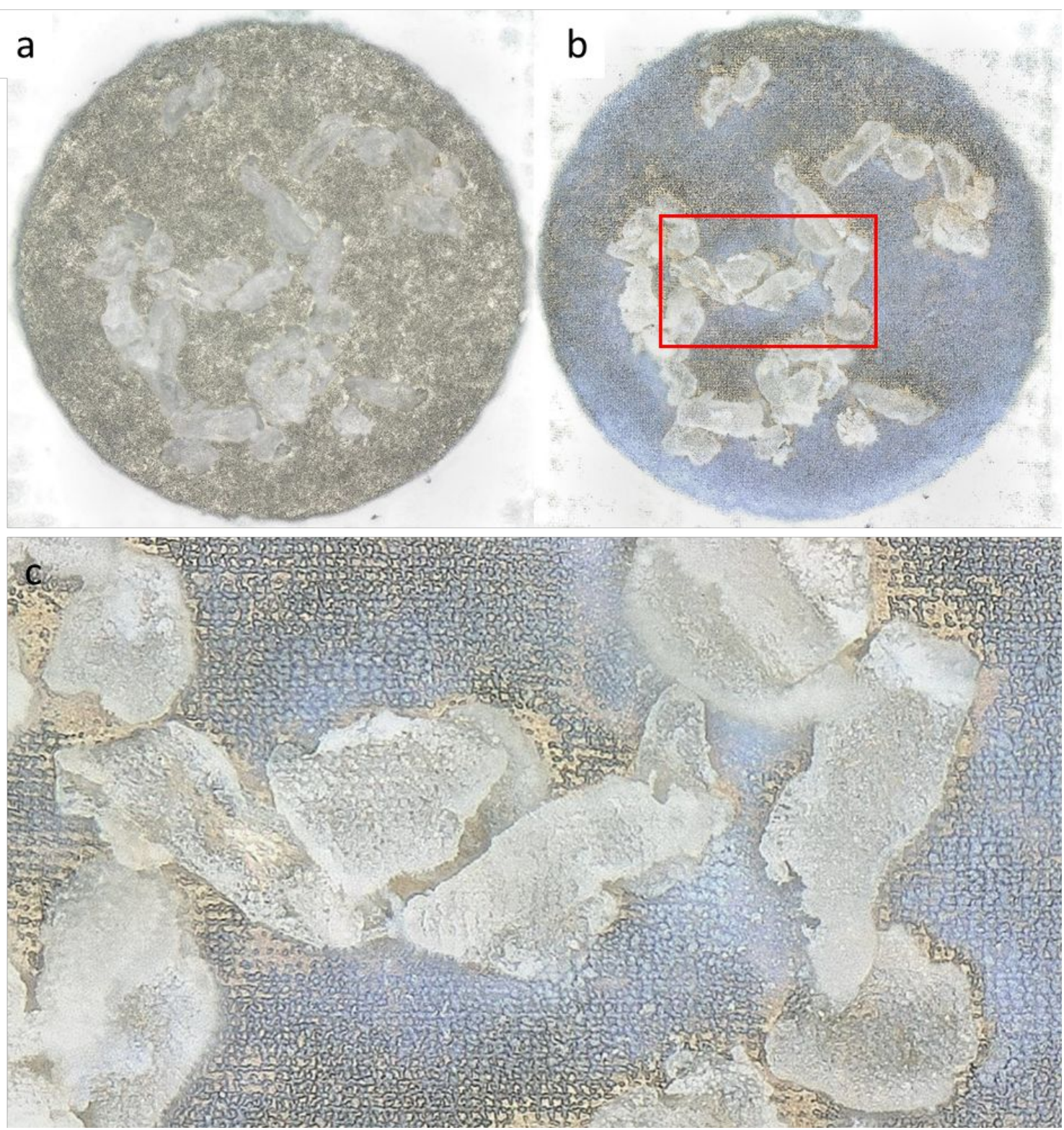
Figure S3: (a) Optical image of a PS microplastic sample after matrix application. (b) Optical image of the same PS microplastic sample after MALDI MSI analysis. (c) Magnification of the marked area, showing uniform laser ablation marks throughout the sample height profile.

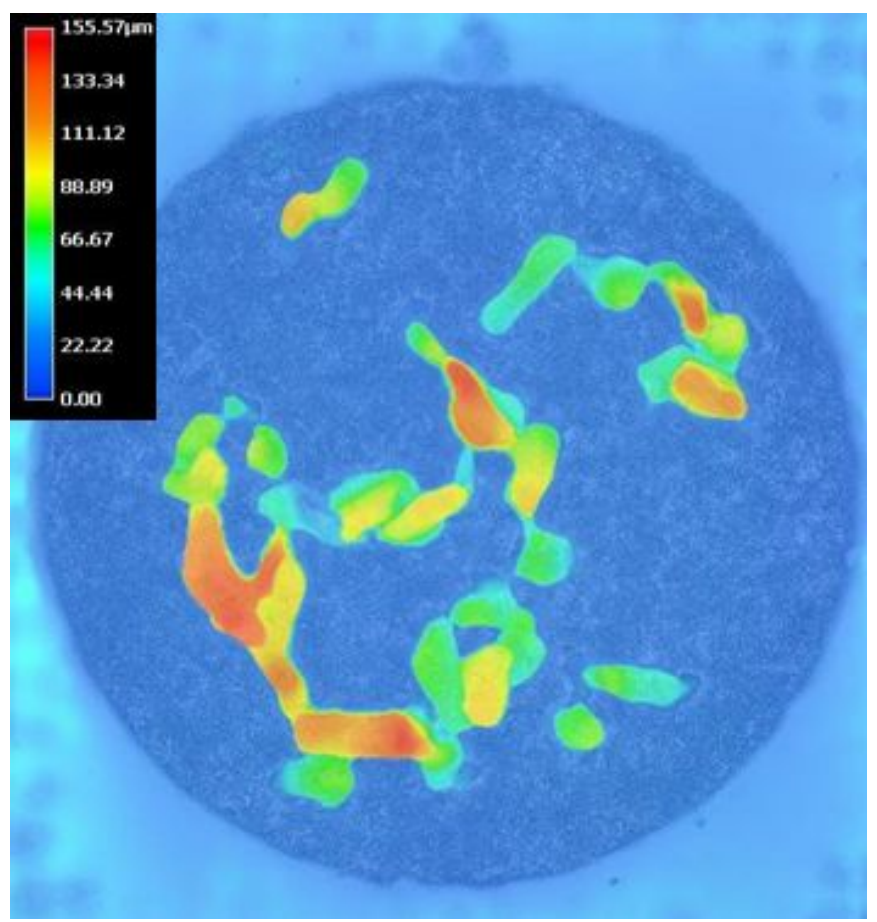

Figure S4: Topography image of PS microplastic showing height variations up to $155 \mu \mathrm{m}$.
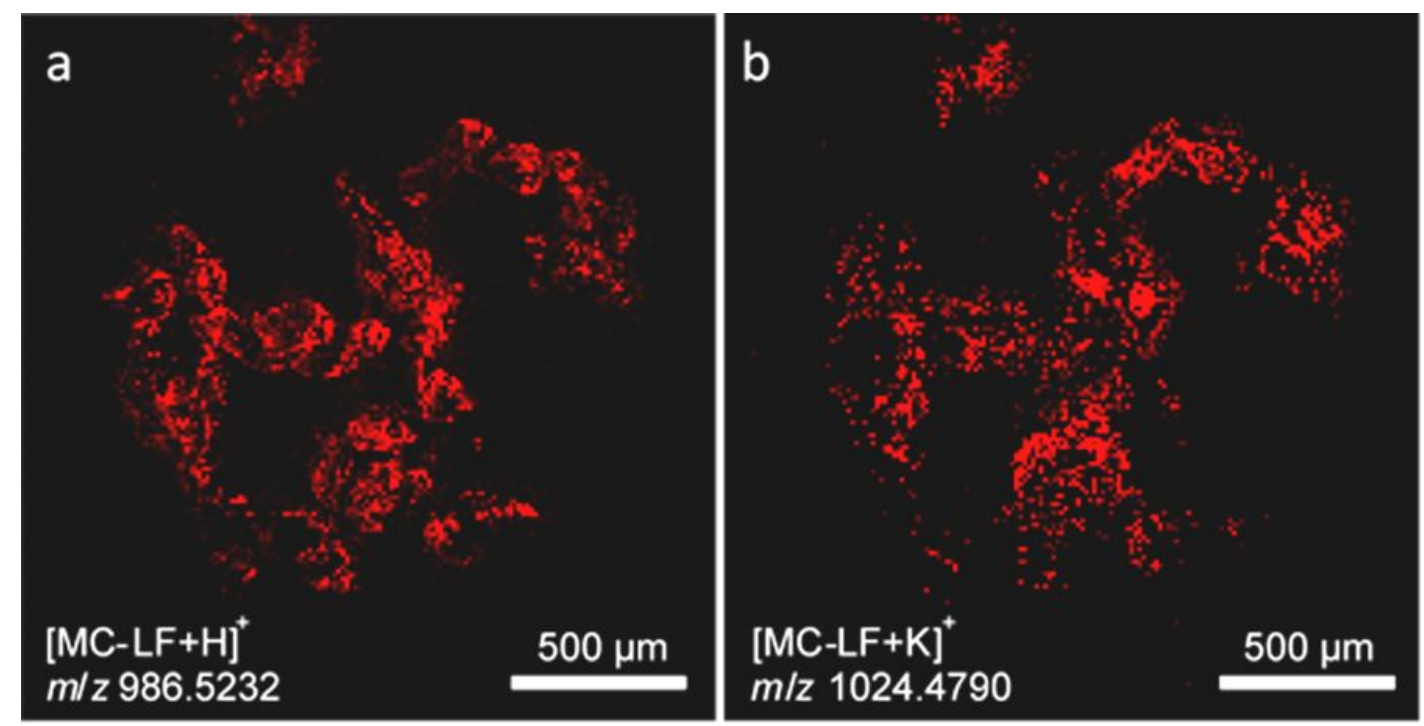

Figure S5: 3D-surface MALDI MS images showing the spatial distributions of (a) [MC$\mathrm{LF}+\mathrm{H}]^{+}$at $\mathrm{m} / \mathrm{z} 986.5232$ and (b) $[\mathrm{MC}-\mathrm{LF}+\mathrm{K}]^{+}$at $\mathrm{m} / \mathrm{z} 1024.4790$ in red. MS images were generated with $170 \times 174$ pixel, $12 \mu \mathrm{m} * 12 \mu \mathrm{m}$ pixel size, image bin width: $\Delta(\mathrm{m} / \mathrm{z})=0.01$. The scale bars are $500 \mu \mathrm{m}$. 


\section{S4: Prediction of toxin concentration per particle of plastic}

Having established the concentration of MC-LR and -LF after $48 \mathrm{~h}$ of exposure

(table S1) allows for the determination of the amount of plastic per particle, allowing for a number of assumptions.

Table S1: Concentration of MC-LR and -LF per gram of plastic after 48 hours of exposure. (Experimental conditions: $10 \mathrm{~g} \mathrm{~L}^{-1}$ plastic, $5 \mu \mathrm{g} \mathrm{L}^{-1} \mathrm{MC}$, horizontal agitation in the dark, $\left.\mathrm{pH} 7,25^{\circ} \mathrm{C}\right)$.

\begin{tabular}{ccc}
\hline Plastic & MC-LR $\left(\boldsymbol{\mu g} \mathbf{~ g}^{-\mathbf{1}}\right)$ & MC-LF $\left(\boldsymbol{\mu g ~ ~ ^ { - 1 }}\right)$ \\
\hline PET & 23.61 & 142.31 \\
PVC & 0 & 0 \\
\hline PE & 13.85 & 96.69 \\
\hline PS & 1.06 & 91.23
\end{tabular}

Determination was performed for $\mathrm{pH} 7$ results only, as this is the most

environmentally relevant $\mathrm{pH}$ condition tested and the smallest particle size

employed in the study. As the particle preparation of blending with subsequent sieving yields particle size ranges rather than single sizes, the first assumption was an average particle size of $0.1075 \mathrm{~mm}$ from the 0.09 to $0.125 \mathrm{~mm}$ range. In order to be able to calculate the amount of toxin per particle, the volume of the particle needs to be determined (Equation S1), this can only be done by assuming perfect sphericity of the particles.

$$
V=\frac{4}{3} \pi r^{2}
$$
where:

$\mathrm{V}=$ volume of the particle; $r=$ radius of the plastic particle 
201 Equation S2:

\section{where:} S2). $\mathrm{pH} 7,25^{\circ} \mathrm{C}$ ).

Then using the densities of the different types of plastic (as stated by the supplier) the weight of each particle can be determined (Equation S2).

$\rho=$ density of the plastic; $m=$ mass of the particle; $v=$ volume of the particle

Combining the information of the amount of MCs per mass for each of the four plastics tested, the amount of toxin per plastic particle can be determined (Table

Table S2: Amount of MC-LR and -LF per plastic particle after 48 hours of exposure. (Experimental conditions: $10 \mathrm{~g} \mathrm{~L}^{-1}$ plastic, $5 \mu \mathrm{g} \mathrm{L}-1 \mathrm{MC}$, horizontal agitation in the dark,

\begin{tabular}{|c|c|c|}
\hline Plastic & MC-LR (pg particle ( $^{-1}$ ) & MC-LF (pg particle-1) \\
\hline PET & 0 & 0 \\
\hline PVC & 12.4 & 86.7 \\
\hline PE & 0.64 & 55.1 \\
\hline PS & 23.6 & 127 \\
\hline
\end{tabular}

S5: Evaluation of the electrostatic charge of each type of microplastics under five pH conditions

Table S3: Zeta potential measurement $(\mathrm{mV})$ of polyethylene terephthalate (PET), polyvinyl chloride (PVC), polyethylene (PE), and polystyrene (PS) in artificial freshwater at $\mathrm{pH} 3, \mathrm{pH} 5, \mathrm{pH} 7, \mathrm{pH}$, and $\mathrm{pH} 10$.

\begin{tabular}{cccccc}
\hline Plastic & PH 3 & PH 5 & PH 7 & PH 9 & pH 10 \\
\cline { 2 - 6 } & & & mV & & \\
\hline PET & 0.08 & -0.06 & -0.42 & -2.50 & -5.66 \\
\hline PVC & 0.06 & -6.20 & -10.96 & -10.89 & -2.96 \\
\hline PE & -10.88 & -5.62 & -12.63 & -0.19 & 0.17 \\
\hline PS & -4.17 & -2.90 & -24.37 & -11.88 & 0.03 \\
\hline
\end{tabular}




\section{S6: Statistical analysis}

\section{S6.1: Significance testing performed using T-test comparing samples}

\section{with the control (no plastics)}

229 The sample data $(n=3)$ were compared with the control data $(n=3)$ to evaluate

whether the microcystin adsorption occurred was significant. $P$-values lower than

0.05 (5 percent) were considered as significant different from the control,

232 therefore the occurrence of adsorption was assumed (Table S4).

Table S4: $P$-values of t-test significance testing comparing the samples $(n=3)$ with the control $(n=3$, no plastics). $P$-values $>0.05$ (red) adsorption cannot be assumed, $p$ values $<0.05$ (green) adsorption can be assumed. SZ-A represents the small size (0.09$0.125 \mathrm{~mm}), \mathrm{SZ}-\mathrm{B}$ represents the medium size $(0.25-0.50 \mathrm{~mm}), \mathrm{SZ}-\mathrm{C}$ represents the large size $(1-5 \mathrm{~mm})$, and the letter $C$ represents the control.

\begin{tabular}{|c|c|c|c|c|c|c|c|c|c|c|}
\hline \multirow[t]{2}{*}{ PET } & \multicolumn{2}{|c|}{ pH 2} & \multicolumn{2}{|c|}{ pH 5} & \multicolumn{2}{|c|}{ pH 7} & \multicolumn{2}{|c|}{ pH 9} & \multicolumn{2}{|c|}{ pH 11} \\
\hline & $\begin{array}{l}\text { MC- } \\
\text { LR }\end{array}$ & $\begin{array}{c}\text { MC - } \\
\text { LF }\end{array}$ & $\begin{array}{c}\text { MC- } \\
\text { LR }\end{array}$ & $\begin{array}{c}\text { MC - } \\
\text { LF }\end{array}$ & $\begin{array}{l}\text { MC- } \\
\text { LR }\end{array}$ & $\begin{array}{c}\text { MC - } \\
\text { LF }\end{array}$ & $\begin{array}{c}\text { MC- } \\
\text { LR }\end{array}$ & $\begin{array}{c}\text { MC - } \\
\text { LF }\end{array}$ & $\begin{array}{c}\text { MC- } \\
\text { LR }\end{array}$ & $\begin{array}{c}\text { MC - } \\
\text { LF }\end{array}$ \\
\hline SZ-A $(2 h) \times C(2 h)$ & 0.11 & 0.01 & 0.61 & 0.83 & 0.93 & 0.32 & 0.13 & 0.72 & 0.23 & 0.22 \\
\hline SZ-B $(2 h) \times C(2 h)$ & 0.20 & 0.23 & 0.74 & 0.87 & 0.08 & 0.39 & 0.10 & 0.11 & 0.28 & 0.61 \\
\hline$S z-C(2 h) \times C(2 h)$ & 0.60 & 0.29 & 0.73 & 0.64 & 0.11 & 0.20 & 0.11 & 0.40 & 0.19 & 0.16 \\
\hline$S Z-A(6 h) \times C(6 h)$ & 0.93 & 0.02 & 0.30 & 0.89 & 0.54 & 0.50 & 0.08 & 0.09 & 0.36 & 0.22 \\
\hline$S Z-B(6 h) \times C(6 h)$ & 0.95 & 0.55 & 0.30 & 0.24 & 0.29 & 0.79 & 0.08 & 0.92 & 0.30 & 0.85 \\
\hline$S Z-C(6 h) \times C(6 h)$ & 0.56 & 0.48 & 0.27 & 0.23 & 0.25 & 0.14 & 0.09 & 0.49 & 0.39 & 0.65 \\
\hline$S Z-A(12 h) \times C(12 h)$ & 0.01 & 0.00 & 0.11 & 0.14 & 0.01 & 0.09 & 0.01 & 0.02 & 0.04 & 0.03 \\
\hline SZ-B(12h)xC(12h) & 0.63 & 0.14 & 0.67 & 0.13 & 0.13 & 0.89 & 0.23 & 0.80 & 0.89 & 0.08 \\
\hline SZ-C(12h)xC(12h) & 0.55 & 0.45 & 0.57 & 0.04 & 0.00 & 0.37 & 0.34 & 0.79 & 0.11 & 0.13 \\
\hline SZ-A(24h)xC(24h) & 0.31 & 0.01 & 0.41 & 0.62 & 0.62 & 0.48 & 0.36 & 0.50 & 0.22 & 0.64 \\
\hline SZ-B(24h)xC(24h) & 0.34 & 0.75 & 0.65 & 0.04 & 0.52 & 0.75 & 0.10 & 0.44 & 0.27 & 0.54 \\
\hline$S Z-C(24 h) \times C(12 h)$ & 0.10 & 0.02 & 0.26 & 0.01 & 0.36 & 0.34 & 0.20 & 0.59 & 0.31 & 0.18 \\
\hline SZ-A(48h)xC(48h) & 0.25 & 0.06 & 0.07 & 0.35 & 0.56 & 0.96 & 0.13 & 0.18 & 0.47 & 0.38 \\
\hline SZ-B(48h)xC(48h) & 0.39 & 0.01 & 0.23 & 0.09 & 0.38 & 0.05 & 0.24 & 0.11 & 0.22 & 0.69 \\
\hline SZ-C(48h)xC(48h) & 0.99 & 0.22 & 0.17 & 0.63 & 0.26 & 0.06 & 0.15 & 0.03 & 0.16 & 0.60 \\
\hline \multirow[b]{2}{*}{ PE } & \multicolumn{2}{|c|}{$\mathrm{pH} 2$} & \multicolumn{2}{|c|}{ pH 5} & \multicolumn{2}{|c|}{$\mathrm{pH} 7$} & \multicolumn{2}{|c|}{$\mathrm{pH} 9$} & \multicolumn{2}{|c|}{$\mathrm{pH} 11$} \\
\hline & $\begin{array}{l}\text { MC- } \\
\text { LR }\end{array}$ & $\begin{array}{c}\text { MC - } \\
\text { LF }\end{array}$ & $\begin{array}{c}\text { MC- } \\
\text { LR }\end{array}$ & $\begin{array}{c}\text { MC - } \\
\text { LF }\end{array}$ & $\begin{array}{l}\text { MC- } \\
\text { LR }\end{array}$ & $\begin{array}{l}\text { MC - } \\
\text { LF }\end{array}$ & $\begin{array}{c}\text { MC- } \\
\text { LR }\end{array}$ & $\begin{array}{c}\text { MC - } \\
\text { LF }\end{array}$ & $\begin{array}{c}\text { MC- } \\
\text { LR }\end{array}$ & $\begin{array}{c}\text { MC - } \\
\text { LF }\end{array}$ \\
\hline$S Z-A(2 h) \times C(2 h)$ & 0.02 & 0.00 & 0.15 & 0.07 & 0.21 & 0.16 & 0.91 & 0.03 & 0.10 & 0.03 \\
\hline SZ-B $(2 h) \times C(2 h)$ & 0.10 & 0.01 & 0.03 & 0.70 & 0.46 & 0.85 & 0.35 & 0.15 & 0.25 & 0.22 \\
\hline$S Z-C(2 h) \times C(2 h)$ & 0.23 & 0.17 & 0.08 & 0.80 & 0.08 & 0.56 & 0.13 & 0.98 & 0.40 & 0.25 \\
\hline$S Z-A(6 h) \times C(6 h)$ & 0.25 & 0.05 & 0.69 & 0.04 & 0.34 & 0.05 & 0.25 & 0.00 & 0.81 & 0.00 \\
\hline
\end{tabular}




\begin{tabular}{|c|c|c|c|c|c|c|c|c|c|c|}
\hline$S Z-B(6 h) \times C(6 h)$ & 0.36 & 0.03 & 0.23 & 0.02 & 0.49 & 0.24 & 0.38 & 0.04 & 0.28 & 0.02 \\
\hline$S Z-C(6 h) \times C(6 h)$ & 0.47 & 0.79 & 0.17 & 0.05 & 0.27 & 0.01 & 0.12 & 0.07 & 0.45 & 0.12 \\
\hline SZ-A(12h)xC(12h) & 0.01 & 0.00 & 0.17 & 0.03 & 0.02 & 0.00 & 0.02 & 0.00 & 0.01 & 0.00 \\
\hline SZ-B(12h)xC(12h) & 0.36 & 0.07 & 0.94 & 0.01 & 0.37 & 0.25 & 0.48 & 0.07 & 0.06 & 0.32 \\
\hline SZ-C(12h)xC(12h) & 0.78 & 0.64 & 0.72 & 0.02 & 0.12 & 0.70 & 0.28 & 0.87 & 0.10 & 0.14 \\
\hline SZ-A(24h)xC(24h) & 0.12 & 0.00 & 0.72 & 0.01 & 0.17 & 0.01 & 0.35 & 0.00 & 0.75 & 0.00 \\
\hline SZ-B(24h)xC(24h) & 0.18 & 0.02 & 0.84 & 0.24 & 0.82 & 0.01 & 0.16 & 0.03 & 0.53 & 0.02 \\
\hline SZ-C(24h)xC(12h) & 0.25 & 0.33 & 0.75 & 0.21 & 0.35 & 0.86 & 0.02 & 0.60 & 0.63 & 0.24 \\
\hline SZ-A(48h)xC(48h) & 0.07 & 0.03 & 0.28 & 0.05 & 0.83 & 0.00 & 0.51 & 0.01 & 0.31 & 0.02 \\
\hline SZ-B(48h)xC(48h) & 0.03 & 0.09 & 0.71 & 0.09 & 0.70 & 0.00 & 0.24 & 0.18 & 0.16 & 0.03 \\
\hline \multirow[t]{2}{*}{ SZ-C(48h)xC(48h) } & 0.05 & 0.19 & 0.09 & 0.12 & 0.07 & 0.06 & 0.20 & 0.05 & 0.04 & 0.12 \\
\hline & \multicolumn{2}{|c|}{$\mathrm{pH} 2$} & \multicolumn{2}{|c|}{$\mathrm{pH} 5$} & \multicolumn{2}{|c|}{$\mathrm{pH} 7$} & \multicolumn{2}{|c|}{$\mathrm{pH} 9$} & \multicolumn{2}{|c|}{$\mathrm{pH} 11$} \\
\hline PVC & $\begin{array}{l}\text { MC- } \\
\text { LR }\end{array}$ & $\begin{array}{c}\text { MC - } \\
\text { LF }\end{array}$ & $\begin{array}{c}\text { MC- } \\
\text { LR }\end{array}$ & $\begin{array}{c}\text { MC - } \\
\text { LF }\end{array}$ & $\begin{array}{l}\text { MC- } \\
\text { LR }\end{array}$ & $\begin{array}{c}\text { MC - } \\
\text { LF }\end{array}$ & $\begin{array}{l}\text { MC- } \\
\text { LR }\end{array}$ & $\begin{array}{c}\text { MC - } \\
\text { LF }\end{array}$ & $\begin{array}{l}\text { MC- } \\
\text { LR }\end{array}$ & $\begin{array}{c}\text { MC - } \\
\text { LF }\end{array}$ \\
\hline SZ-A(2h)xC(2h) & 0.00 & 0.01 & 0.41 & 0.07 & 0.13 & 0.08 & 0.89 & 0.01 & 0.11 & 0.06 \\
\hline SZ-B(2h)xC(2h) & 0.07 & 0.03 & 0.10 & 0.80 & 0.18 & 0.47 & 0.28 & 0.15 & 0.48 & 0.34 \\
\hline$S Z-C(2 h) \times C(2 h)$ & 0.05 & 0.16 & 0.02 & 0.49 & 0.10 & 0.34 & 0.10 & 0.02 & 0.37 & 0.52 \\
\hline$S Z-A(6 h) \times C(6 h)$ & 0.01 & 0.03 & 0.50 & 0.05 & 0.13 & 0.01 & 0.26 & 0.00 & 0.59 & 0.02 \\
\hline$S Z-B(6 h) \times C(6 h)$ & 0.68 & 0.06 & 0.26 & 0.11 & 0.91 & 0.22 & 0.66 & 0.05 & 0.51 & 0.05 \\
\hline$S Z-C(6 h) \times C(6 h)$ & 0.22 & 0.68 & 0.28 & 0.08 & 0.68 & 0.69 & 0.11 & 0.02 & 0.34 & 0.65 \\
\hline$S Z-A(12 h) \times C(12 h)$ & 0.03 & 0.01 & 0.24 & 0.04 & 0.01 & 0.00 & 0.01 & 0.01 & 0.00 & 0.00 \\
\hline SZ-B(12h)xC(12h) & 0.41 & 0.07 & 0.91 & 0.01 & 0.79 & 0.24 & 0.45 & 0.08 & 0.21 & 0.01 \\
\hline SZ-C(12h)xC(12h) & 0.54 & 0.20 & 0.84 & 0.03 & 0.82 & 0.05 & 0.79 & 0.10 & 0.19 & 0.07 \\
\hline SZ-A(24h)xC(24h) & 0.28 & 0.00 & 0.79 & 0.01 & 0.09 & 0.06 & 0.02 & 0.01 & 0.52 & 0.00 \\
\hline SZ-B(24h)xC(24h) & 0.08 & 0.00 & 0.65 & 1.00 & 0.71 & 0.04 & 0.15 & 0.11 & 0.52 & 0.01 \\
\hline$S Z-C(24 h) \times C(12 h)$ & 0.12 & 0.05 & 0.64 & 0.11 & 0.54 & 0.50 & 0.26 & 0.10 & 0.41 & 0.26 \\
\hline SZ-A(48h)xC(48h) & 0.37 & 0.00 & 0.40 & 0.03 & 0.17 & 0.00 & 0.04 & 0.00 & 0.83 & 0.01 \\
\hline SZ-B(48h)xC(48h) & 0.15 & 0.04 & 0.39 & 0.49 & 0.87 & 0.17 & 0.36 & 0.11 & 0.11 & 0.17 \\
\hline \multirow[t]{2}{*}{ SZ-C(48h)xC(48h) } & 0.50 & 0.17 & 0.27 & 0.00 & 0.37 & 0.78 & 0.43 & 0.02 & 0.07 & 0.14 \\
\hline & \multicolumn{2}{|c|}{$\mathrm{pH} 2$} & \multicolumn{2}{|c|}{$\mathrm{pH} 5$} & \multicolumn{2}{|c|}{$\mathrm{pH} 7$} & \multicolumn{2}{|c|}{$\mathrm{pH} 9$} & \multicolumn{2}{|c|}{$\mathrm{pH} 11$} \\
\hline PS & $\begin{array}{c}\text { MC- } \\
\text { LR }\end{array}$ & $\begin{array}{c}\text { MC - } \\
\text { LF }\end{array}$ & $\begin{array}{c}\text { MC- } \\
\text { LR }\end{array}$ & $\begin{array}{c}\text { MC - } \\
\text { LF }\end{array}$ & $\begin{array}{c}\text { MC- } \\
\text { LR }\end{array}$ & $\begin{array}{c}\text { MC - } \\
\text { LF }\end{array}$ & $\begin{array}{c}\text { MC- } \\
\text { LR }\end{array}$ & $\begin{array}{c}\text { MC - } \\
\text { LF }\end{array}$ & $\begin{array}{c}\text { MC- } \\
\text { LR }\end{array}$ & $\begin{array}{c}\text { MC - } \\
\text { LF }\end{array}$ \\
\hline SZ-A(2h)xC(2h) & 0.02 & 0.00 & 0.08 & 0.02 & 0.00 & 0.02 & 0.07 & 0.01 & 0.51 & 0.00 \\
\hline SZ-B(2h)xC(2h) & 0.91 & 0.03 & 0.66 & 0.19 & 0.52 & 0.71 & 0.21 & 0.05 & 0.17 & 0.02 \\
\hline$S Z-C(2 h) \times C(2 h)$ & 0.96 & 0.37 & 0.29 & 0.90 & 0.10 & 0.48 & 0.12 & 0.30 & 0.14 & 0.32 \\
\hline$S Z-A(6 h) \times C(6 h)$ & 0.23 & 0.06 & 0.30 & 0.01 & 0.05 & 0.01 & 0.02 & 0.00 & 0.18 & 0.00 \\
\hline SZ-B(6h)xC(6h) & 0.45 & 0.02 & 0.90 & 0.89 & 0.66 & 0.06 & 0.93 & 0.00 & 0.40 & 0.10 \\
\hline$S z-c(6 h) \times C(6 h)$ & 0.47 & 0.12 & 0.50 & 0.02 & 0.23 & 0.54 & 0.15 & 0.09 & 0.59 & 0.11 \\
\hline$S Z-A(12 h) \times C(12 h)$ & 0.05 & 0.00 & 0.47 & 0.02 & 0.01 & 0.00 & 0.01 & 0.00 & 0.01 & 0.00 \\
\hline SZ-B(12h)xC(12h) & 0.47 & 0.04 & 0.77 & 0.02 & 0.50 & 0.13 & 0.76 & 0.02 & 0.21 & 0.10 \\
\hline $\operatorname{SZ}-C(12 \mathrm{~h}) \times C(12 \mathrm{~h})$ & 0.53 & 0.41 & 0.37 & 0.08 & 0.16 & 0.84 & 0.28 & 0.08 & 0.19 & 0.04 \\
\hline SZ-A(24h)xC(24h) & 0.05 & 0.00 & 0.04 & 0.00 & 0.02 & 0.00 & 0.03 & 0.00 & 0.17 & 0.00 \\
\hline SZ-B(24h)xC(24h) & 0.21 & 0.00 & 0.44 & 0.55 & 0.84 & 0.35 & 0.25 & 0.03 & 0.28 & 0.07 \\
\hline SZ-C(24h)xC(12h) & 0.38 & 0.64 & 0.32 & 0.52 & 0.42 & 0.11 & 0.29 & 0.45 & 0.35 & 0.78 \\
\hline SZ-A(48h)xC(48h) & 0.09 & 0.00 & 0.05 & 0.01 & 0.01 & 0.00 & 0.01 & 0.00 & 0.98 & 0.02 \\
\hline SZ-B(48h)xC(48h) & 0.19 & 0.02 & 0.50 & 0.26 & 0.50 & 0.02 & 0.96 & 0.08 & 0.08 & 0.09 \\
\hline SZ-C(48h)xC(48h) & 0.22 & 0.27 & 0.88 & 0.08 & 0.37 & 0.38 & 0.82 & 0.34 & 0.34 & 0.41 \\
\hline
\end{tabular}


Table S5: Pearson correlation coefficients $\left(R^{2}\right)$ evaluating the correlation between the plastic type, MC-LR and -LF adsorption after $48 \mathrm{~h}$ contact, average sorption capacity ranking, and glass transition temperature

PLASTIC

$\begin{array}{cc}\text { MC-LR } & \text { MC-LF } \\ \text { adsorption } & \text { adsorption }\end{array}$

\begin{tabular}{lc}
$\begin{array}{l}\text { Average } \\
\text { sorption } \\
\text { capacity } \\
\text { ranking }\end{array}$ & $\begin{array}{c}\text { Glass } \\
\text { transition } \\
\text { temperature }\end{array}$ \\
\hline
\end{tabular}

PLASTIC 1.00

MC-LR adsorption $\quad 0.96$

MC-LF adsorption

$0.96 \quad 1.00$

Average sorption

capacity ranking

0.94

0.80

1.00

Glass transition

$-0.68$

$-0.47$

$-0.89$

1.00

temperature

0.37

0.60

0.02

0.43

1.00

\section{References}

(1) Eerkes-Medrano, D.; Thompson, R. C.; Aldridge, D. C. Microplastics in

(2) Li, J.; Liu, H.; Paul Chen, J. Microplastics in Freshwater Systems: A Review on Occurrence, Environmental Effects, and Methods for Microplastics

Detection. Water Res. 2018, 137, 362-374.

(3) Barnes, D. K. A.; Galgani, F.; Thompson, R. C.; Barlaz, M. Accumulation and Fragmentation of Plastic Debris in Global EnvirBarnes, D. K. A., F. Galgani, R. C. Thompson, and M. Barlaz. 2009. "Accumulation and Fragmentation of Plastic Debris in Global Environments." Philosophical Transactions of the Royal Society B. Philos. Trans. R. Soc. B Biol. Sci. 2009, 364 (1526), 1985-1998. https://doi.org/10.1098/rstb.2008.0205. 
(4) Fendall, L. S.; Sewell, M. A. Contributing to Marine Pollution by Washing Your Face: Microplastics in Facial Cleansers . Marine Pollution Bulletin , 58, 1225-1228. Mar. Pollut. Bull. 2016, 58 (April), 1225-1228. https://doi.org/10.1016/j.marpolbul.2009.04.025.

(5) Alimi, O. S.; Farner Budarz, J.; Hernandez, L. M.; Tufenkji, N. Microplastics and Nanoplastics in Aquatic Environments: Aggregation, Deposition, and Enhanced Contaminant Transport. Environ. Sci. Technol. 2018, 52 (4), 1704-1724. https://doi.org/10.1021/acs.est.7b05559. 